With compliments of the Author 


\title{
Enantioselective Synthesis of Indole Alkaloids from Chiral Lactams
}

\author{
Mercedes Amat,* Maria Pérez, Joan Bosch \\ Laboratory of Organic Chemistry, Faculty of Pharmacy, and Institute of Biomedicine (IBUB), University of Barcelona, \\ Av. Joan XXIII s/n, 08028 Barcelona, Spain \\ Fax +34(93)4024539; E-mail: amat@ub.edu \\ Received 20 October 2010
}

\begin{abstract}
This account reports on the use of $(R)$ - or $(S)$-phenylglycinol- and ( $S$ )-tryptophanol-derived oxazolopiperidone lactams as building blocks for the enantioselective synthesis of structurally diverse indole alkaloids.
\end{abstract}

1 Introduction

2 Monoterpenoid Indole Alkaloids from $(R)$ - or $(S)$-Phenylglycinol-Derived Lactams

2.1 Substituted Piperidines as Precursors for the Enantioselective Synthesis of Indole Alkaloids

2.1.1 (+)-Decarbomethoxytetrahydrosecodine

2.1.2 Enantiopure cis- and trans-(3-Ethylpiperidin-4-yl)acetates as Precursors for the Synthesis of Indolo- and Benzo[a]quinolizidine Alkaloids

2.1.3 Indole Alkaloids Related to Cleavamine and Quebrachamine

2.2 Uleine and Strychnos Alkaloids

2.3 The Ervatamine-Silicine Group

3 Indolo[2,3-a]quinolizidines from (S)-TryptophanolDerived Lactams

3.1 Indolo[2,3- $a$ ]quinolizidines and Analogues by Intramolecular Amidoalkylation Reactions: Synthesis of $(R)-(+)-$ Deplancheine and $(R)-(+)$-Harmicine

3.2 Indolo[2,3- $a$ ]quinolizidines by a Modified BischlerNapieralski Reaction: Formal Synthesis of (+)-Dihydrocorynantheine and (-)-Dihydrocorynantheol

4 Conclusion

Key words: alkaloids, lactams, indoles, stereoselective synthesis, total synthesis

\section{Introduction}

The piperidine ring can be recognized not only in the structure of more than half of the alkaloids known today, but also in many natural or synthetic compounds with interesting biological activities. ${ }^{1}$ For this reason, the search for new and efficient methodologies for the enantioselective synthesis of diversely substituted piperidine derivatives has gained the attention of many synthetic organic chemists in the last couple of decades. ${ }^{2}$ In this context, in the mid-1990s, we decided to explore the potential of chiral bicyclic lactams as enantiomeric scaffolds for the stereocontrolled construction of complex piperidine derivatives.

SYNLETT 2011, No. 2, pp 0143-0160

Advanced online publication: 04.01.2011

DOI: 10.1055/s-0030-1259297; Art ID: A57610ST

(c) Georg Thieme Verlag Stuttgart · New York
These bicyclic lactams were originally developed by A. I. Meyers as chiral templates for the enantioselective synthesis of carbocycles containing quaternary stereocenters, such as cyclopentenones, cyclohexenones, and hexahydroindenone systems, as well as carboxylic acids. Later on, Meyers described some applications of chiral bicyclic lactams to the enantioselective preparation of nitrogencontaining heterocycles and reported the synthesis of simple piperidine and tetrahydroisoquinoline alkaloids, as well as imino sugars. This excellent work was summarized by Meyers and co-workers in three reviews published in $1991,{ }^{3} 1997,{ }^{4}$ and $2000{ }^{5}$

Several reasons led us to consider chiral bicyclic lactams with an oxazolopiperidone structure (i.e., B, Scheme 1) for our purposes: they are easily accessible in one synthetic step by the cyclocondensation of oxoacid derivatives, i.e. $\mathbf{A}$, with enantiopure amino alcohols, their functionality permits the introduction of substituents on the core piperidine ring, and the conformational rigidity of the amide bicyclic system induces a high degree of stereoselectivity in the generation of new stereocenters. We selected phenylglycinol as the chiral amino alcohol because the phenylethanol moiety of the chiral inductor can be easily removed at an appropriate stage of the synthesis owing to the benzylic nature of the exocyclic carbon-nitrogen bond. In fact, phenylglycinol can be considered as a chiral latent form of ammonia. Moreover, phenylglycinol is commercially available in both enantiomeric forms, thus making both enantiomers of a target compound accessible.
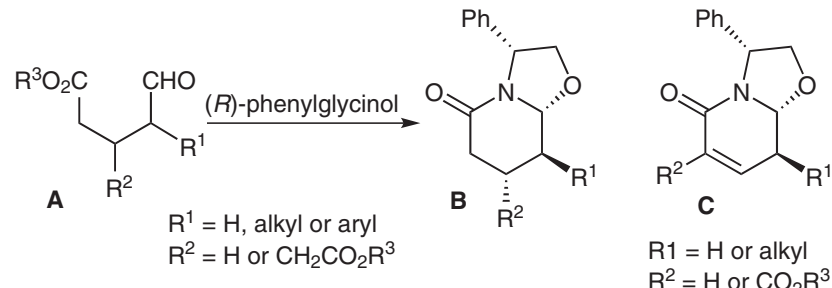

$\mathrm{R}^{2}=\mathrm{H}$ or $\mathrm{CO}_{2} \mathrm{R}^{3}$

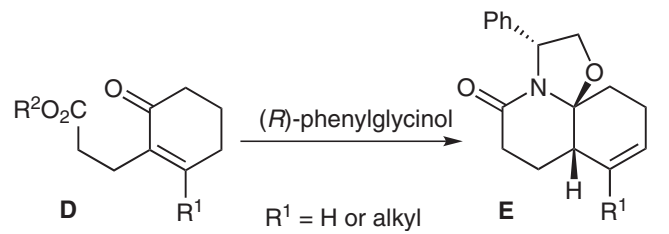

Scheme 1 
In our early work in this field, we used simple bicyclic lactams $\left(B, R^{1}=R^{2}=H\right)$ and explored the stereoselective introduction of carbon substituents, mainly by intermolecular amidoalkylation reactions, lactam enolate alkylations, and conjugate addition reactions (in this case from unsaturated lactams C). ${ }^{6}$ This allowed us to evaluate the scope and limitations of the methodology for the synthesis of diversely substituted piperidines. In subsequent work, we carried out the cyclocondensation reactions of phenylglycinol and racemic $\left(A, R^{1}=\right.$ alkyl or aryl and $\mathrm{R}^{2}$ $=\mathrm{H}$ or $\left.\mathrm{CH}_{2} \mathrm{CO}_{2} \mathrm{R}^{3}\right)$ or prochiral oxoacids $\left[\mathrm{A}, \mathrm{R}^{1}=\mathrm{H}\right.$ and $\mathrm{R}^{2}=\mathrm{CH}_{2} \mathrm{CO}_{2} \mathrm{R}^{3}$ or $\mathrm{R}^{1}=\left(\mathrm{CH}_{2}\right)_{2} \mathrm{CO}_{2} \mathrm{R}^{3}$ and $\left.\mathrm{R}^{2}=\mathrm{H}\right]$, stereoselectively affording bicyclic lactams with carbon substituents at the $\beta$ - and/or $\gamma$-positions of the piperidine ring. In those cases, the cyclocondensation of racemic oxoacids involves dynamic kinetic resolution, whereas desymmetrization takes place using substrates with prochiral carbon atoms. ${ }^{7}$ More recently, we have described the cyclocondensation of substituted 3-(6-oxocyclohexenyl)propanoates D with $(R)$-phenylglycinol (Scheme 1), stereoselectively affording tricyclic lactams E, which constitute excellent precursors of enantiopure cis-decahydroquinoline derivatives. ${ }^{8}$

The synthetic versatility of chiral phenylglycinol-derived bicyclic and tricyclic lactams in the enantioselective synthesis of natural products bearing a piperidine ring structural motif has been demonstrated with the synthesis of

\section{Biographical Sketches}
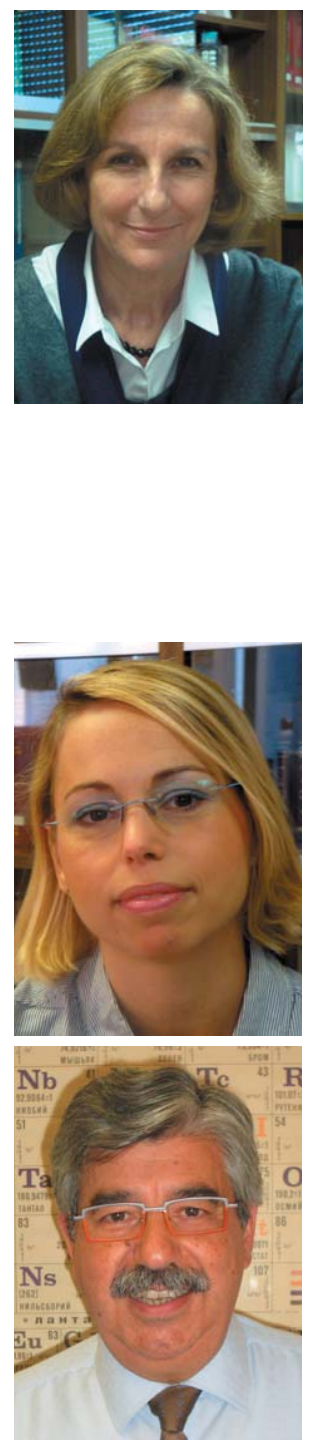

Mercedes Amat was born in Castellón, Spain, in 1956. She graduated in pharmacy at the University of Barcelona in 1979 and completed her Ph.D. at the same university in 1984 under the supervision of Professor Joan Bosch. In 1985, she moved to the University of Virginia, USA, as a Fulbright scholar, where she carried out postdoctoral studies in the laboratory of Professor Richard J. Sundberg, work-

Maria Pérez Bosch was born in Barcelona, Spain, in 1974. She graduated in pharmacy in 1997 and completed her Ph.D. degree in 2002 under the supervision

Joan Bosch was born in Barcelona, Spain, in 1947. $\mathrm{He}$ graduated in chemistry in 1969 and completed his Ph.D. degree in 1973 at the University of Barcelona. He has been Professor of Organic Chemistry since 1982 in the Faculty of Pharmacy of the University of Barcelona. During the period 1983-1986, he was Vice Dean of this faculty and then Dean during 19861992. He was also Director of the Department of Phar- ing on the total synthesis of natural products. In 1986, she was appointed to a permanent position as Associate Professor of Organic Chemistry in the Faculty of Pharmacy of the University of Barcelona, Spain, and in 1997 she was promoted to the position of Full Professor. Since January 2005, she has been Head of the Department of Pharmacology and Medicinal Chemistry of the University of Barcelona.

of Professors Mercedes Amat and Joan Bosch at the University of Barcelona, where she currently holds the position of Assistant Professor. Her research is

macology and Medicinal Chemistry during the period 1992-1998. His research is focused on the development of general methods and strategies for the synthesis of alkaloids, in particular piperidine-containing indole alkaloids. He has published 275 scientific papers and supervised $36 \mathrm{Ph} . D$. theses. $\mathrm{He}$ has been involved in many collaborative projects with chemical and pharmaceutical companies aimed at the synthesis of new thera-
Her current research interests concern the development of new synthetic methods for the enantioselective synthesis of natural products, in particular alkaloids, and other bioactive nitrogen compounds. She has published more than 90 scientific papers and has supervised 13 doctoral theses and several postdoctoral researchers.

currently focused on the use of phenylglycinol-derived lactams as starting materials for the synthesis of complex alkaloids.

peutic agents and the development of new synthetic routes for active pharmaceutical ingredients. As a consequence of this research, he is one of the inventors of 80 patents. In 2002, he was awarded the Distinction for the Promotion of University Research by the Government of Catalunya. Since 2010, he has been President of the Organic Chemistry Division of the Spanish Royal Society of Chemistry. 
several alkaloids, some of them depicted in Figure 1, and pharmacologically active compounds, such as (-)-paroxetine and (-)-3PPP. A medium-sized library of enantiopure, diversely polysubstituted piperidines and piperidine-containing bicyclic systems has also been elaborated in our laboratories.<smiles>CCC[C@H]1CCCCN1</smiles>

(-)-coniine

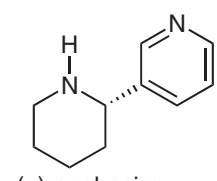

(-)-anabasine

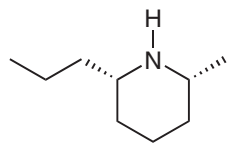

(-)-dihydropinidine

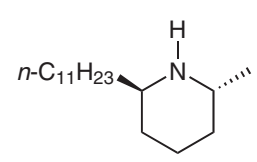

(-)-solenopsin A<smiles>CC1C[C@H](C)C[C@]2(C)CCCCN12</smiles>

(-)-cermizine C

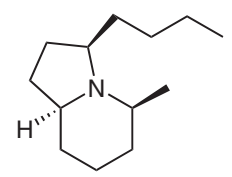

(+)-monomorine |<smiles>CCC[C@@H]1CC[C@H]2[C@@H](C)CCC[C@H]2N1</smiles>

(-)-pumiliotoxin C

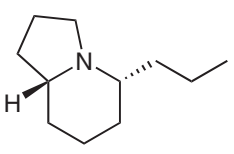

(-)-gephyrotoxin 167B<smiles>OC[C@H]1NC[C@@H](O)[C@H](O)[C@@H]1O</smiles>

1-deoxy-D-gulonojirimycin
Figure 1

Most of this work was surveyed in a previous review published in 2006. ${ }^{9}$ This account focuses specifically on the application of chiral lactams, prepared either from $(R)$ - or $(S)$-phenylglycinol or from $(S)$-tryptophanol, to the synthesis of indole alkaloids. Besides the achievements of our research group in this field, we have also included the closely related work of S. M. Allin ${ }^{10}$ to provide the reader with a broad and up-to-date idea of the subject of this review.

\section{2 \\ Monoterpenoid Indole Alkaloids from $(R)$ - or $(S)$-Phenylglycinol-Derived Lactams}

The monoterpenoid indole alkaloids constitute a large group with a wide variety of complex chemical structures and interesting biological activities. ${ }^{11}$ They originate biogenetically from a single precursor, strictosidine, derived from the joining of tryptamine and the secoiridoid monoterpene secologanin (Scheme 2). The enormous variation in the structure of these alkaloids is associated with the skeletal modifications that the monoterpene $\mathrm{C}_{9} / \mathrm{C}_{10}$ unit undergoes in the biosynthetic route. ${ }^{12}$ Thus, three major types of alkaloids can be broadly distinguished: ${ }^{13}$ the Corynanthe-Strychnos group, with a nonrearranged secologanin skeleton; the Aspidosperma group, formally resulting from cleavage of the $\mathrm{C}-15-\mathrm{C}-16$ bond and formation of a C-17-C-20 bond; and the Iboga group, also with a rearranged monoterpene unit, but in this case after cleavage of the C-15-C-16 bond and combination of the
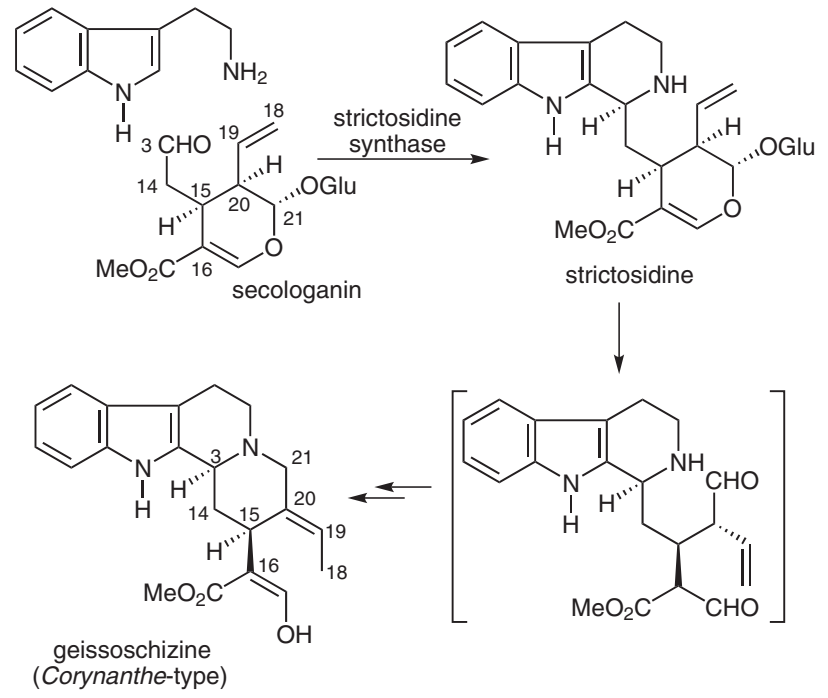

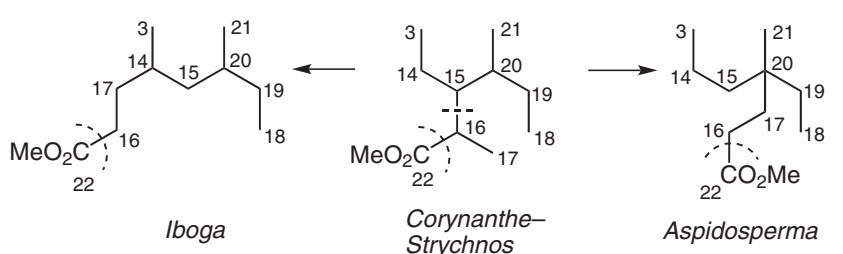

Scheme 2

C-14 and C-17 positions. The tenth atom, C-22, is sometimes missing, resulting in a $\mathrm{C}_{9}$ monoterpenoid unit.

Owing to their biogenetic origin from tryptamine and secologanin, most monoterpenoid indole alkaloids display common structural features, such as the presence of a piperidine ring and a two-carbon substituent at the $\beta$-position (C-18 and C-19).

In this context, and using phenylglycinol-derived bicyclic lactams as the starting enantiomeric scaffolds, we devised the preparation of enantiopure piperidines bearing the appropriate substitution pattern for the synthesis of the target indole alkaloids. In particular, we focused our attention on the preparation of 3-ethylpiperidines with an acetate chain at the 5-, 4-, or 3-position as biogenetic analogues of the $\mathrm{C}_{9}$ monoterpenoid unit of Iboga-, Corynanthe-Strychnos-, and Aspidosperma-type indole alkaloids, respectively (Figure 2).
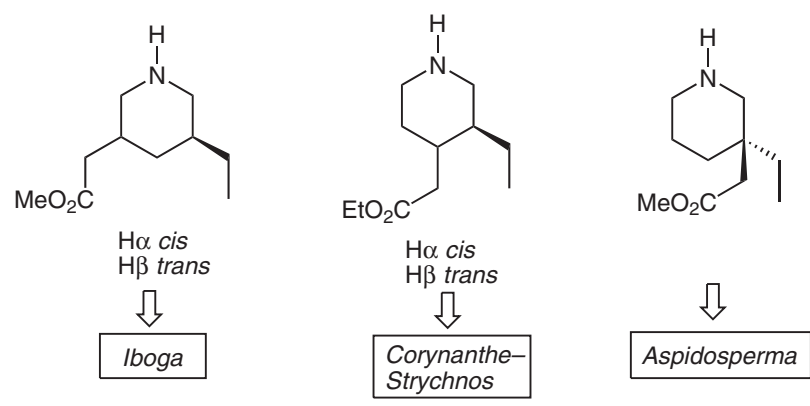

Figure 2 


\subsection{Substituted Piperidines as Precursors for the Enantioselective Synthesis of Indole Alka- loids}

As mentioned above, the presence of a two-carbon appendage (ethyl or ethylidene) at the $\beta$-position of the piperidine ring, biogenetically corresponding to the $\mathrm{C}-18$ and C-19 vinylic carbons of secologanin, constitutes one of the most characteristic structural features of monoterpenoid indole alkaloids. Bearing this in mind, we prepared 8-ethyl-substituted bicyclic lactam $\mathbf{1 A}$ from racemic methyl 4-formylhexanoate and $(R)$-phenylglycinol by cyclocondensation involving dynamic kinetic resolution of the starting racemic formyl-containing ester (Scheme 3). Compound 1A was isolated in 70\% yield along with minor amounts (9\%) of the C-8 and C-8a diastereomer 1B. ${ }^{14}$ Bicyclic lactam 1A constitutes the key enantiomeric scaffold for the preparation of 3-ethyl-substituted piperidine derivatives used in the synthesis of the indole alkaloids described in this section.

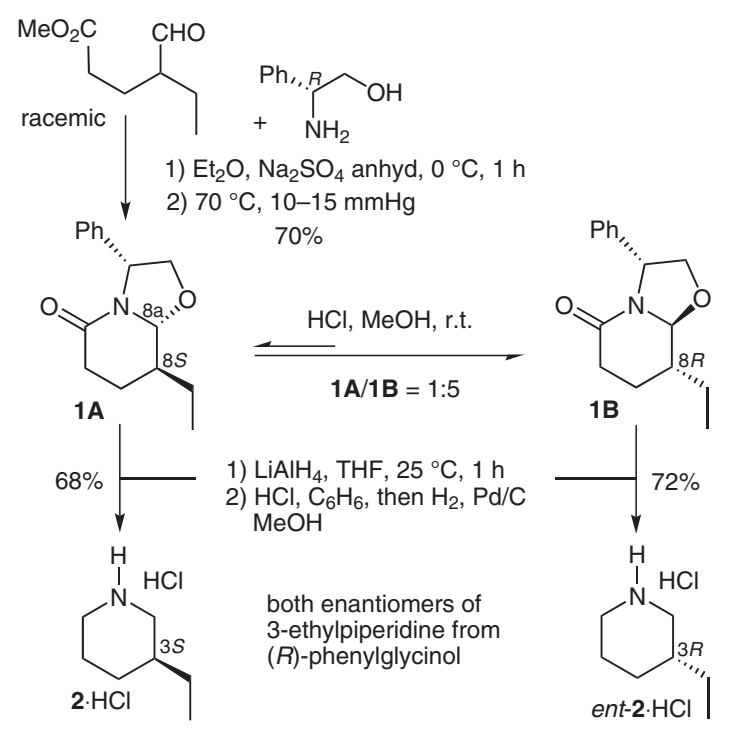

Scheme 3

Compound 1A can be converted into (S)-3-ethylpiperidine (2) by lithium aluminum hydride (LAH) reduction of the amide carbonyl functionality which takes place with simultaneous reductive cleavage of the oxazolidine ring, followed by hydrogenolysis of the resulting $N$-benzylic substituent. (S)-3-Ethylpiperidine (2) was isolated in 68\% yield as the corresponding hydrochloride. However, when lactam $\mathbf{1 A}$ is subjected to acidic conditions, isomerization of the C-8 and C-8a stereocenters occurs affording a mixture in which diastereomer $\mathbf{1 B}$ is the major isomer $[(\mathbf{1 A} /$ 1B) 1:5]. Bicyclic lactam 1B was converted into $(R)-3$ ethylpiperidine (ent-2) following the above procedure. ${ }^{14,15}$ Thus, interestingly, both enantiomers of the 3-alkyl-substituted piperidine are available starting from the same enantiomer of the chiral inductor, $(R)$-phenylglycinol.
An alternative procedure to prepare enantiopure 3-alkylpiperidines involves the stereoselective enolate alkylation of unsubstituted bicyclic lactam 3 (Scheme 4). ${ }^{16}$ Treatment of substrate $\mathbf{3}$ with lithium hexamethyldisilazide followed by the addition of ethyl iodide afforded compound 4 in $83 \%$ yield as the only stereoisomer observable by NMR spectroscopy. Subsequent LAH reduction of ethylsubstituted compound $\mathbf{4}$ followed by removal of the chiral auxiliary by hydrogenolysis gave $(S)$-3-ethylpiperidine $(2)$ in good yield. The corresponding enantiomer, $(R)-3-$ ethylpiperidine (ent-2), was also accessible starting from lactam ent $\mathbf{3}$ prepared from $(S)$-phenylglycinol.

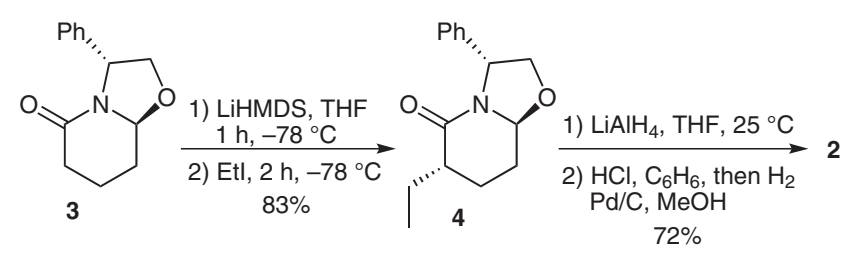

Scheme 4

\subsection{1 (+)-Decarbomethoxytetrahydrosecodine}

The indole alkaloid (+)-(R)-decarbomethoxy15,20,16,17-tetrahydrosecodine [(+)-7], isolated in 1968 from Tabernaemontana cumminsii, is the most-simple secodine-type alkaloid occurring in nature. ${ }^{17}$ The absolute configuration of its only stereocenter was established as $20 R$ when the alkaloid was synthesized in its enantiopure form for the first time. ${ }^{18}$

With an efficient tool in hand for the enantioselective preparation of 3-alkylpiperidines, we decided to synthesize alkaloid (+)-decarbomethoxytetrahydrosecodine (+)7 by $\mathrm{N}$-alkylation of $(R)$-3-ethylpiperidine (ent-2) with 3(2-bromoethyl)-2-ethyl-1H-indole (6). The latter compound was prepared using a procedure previously developed in our laboratory for the generation of 3lithioindoles. ${ }^{19}$ Thus, bromination of 1-(tert-butyldimethylsilyl)-2-ethyl- $1 H$-indole (5) with $N$-bromosuccinimide, followed by lithium-halogen exchange and treatment of the resulting 3-lithioindole with ethylene oxide, afforded the corresponding tryptophol derivative, which was converted into the desired bromide 6 with phosphorus tribromide (Scheme 5).

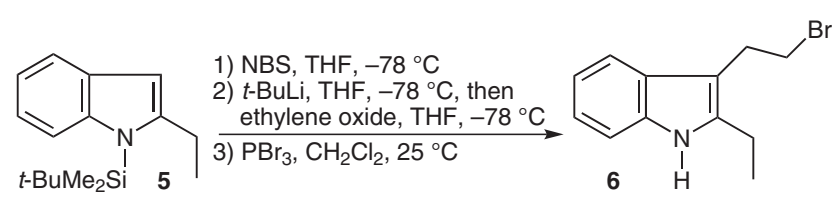

Scheme 5

The target alkaloid (+)-decarbomethoxytetrahydrosecodine (+)-7 was obtained by $\mathrm{N}$-alkylation of $(R)$-3-ethylpiperidine (ent-2) with bromide 6 (Scheme 6). ${ }^{15,16}$ 


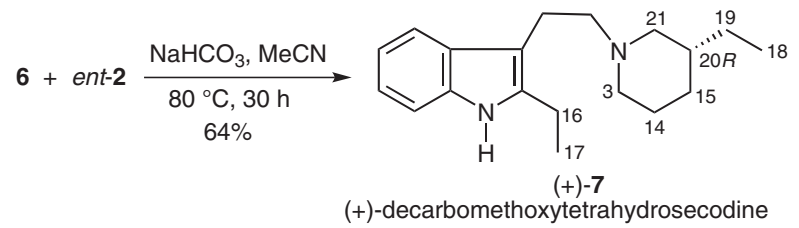

Scheme 6

\subsubsection{Enantiopure cis- and trans-(3-Ethylpiperidin- 4-yl)acetates as Precursors for the Synthesis of Indolo- and Benzo $[a]$ quinolizidine Alkaloids}

3-Ethyl-4-piperineacetates and 4-piperidineethanols are structural moieties present in a number of indole and tetrahydroisoquinoline alkaloids, and have been used as crucial intermediates in the synthesis of these alkaloids (Figure 3). It is worth mentioning that Ipecacuanha alkaloids, such as (-)-emetine, and Alangium alkaloids, such as (-)-ankorine, which have a benzo $[a]$ quinolizidine nucleus are formed in nature from dopamine and the monoterpene secologanin through a biosynthetic pathway that, in the first steps, is closely related to the biosynthesis of monoterpenoid indole alkaloids. ${ }^{20}$ Thus, the structural similarities found in indole and some tetrahydroisoquinoline alkaloids are a consequence of analogies in their biogenetic origin.

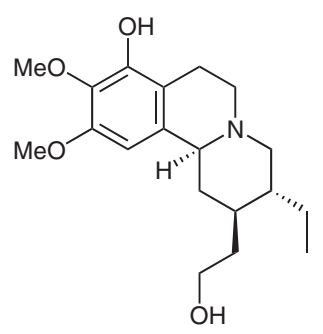

(-)-ankorine

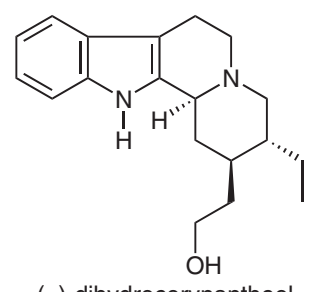

(-)-dihydrocorynantheol

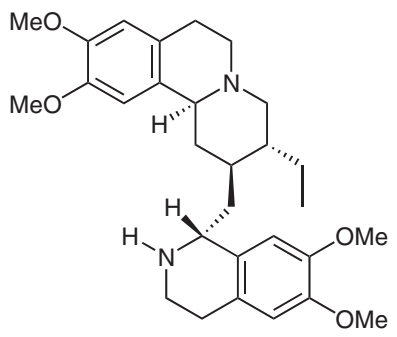

(-)-emetine

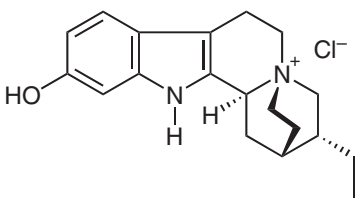

(-)-ophiorrhizine
Figure 3

Although several syntheses of cis- and trans-(3-ethylpiperidin-4-yl)acetates have been described in the racemic series, the preparation of enantiopure derivatives relies mainly on the resolution of racemates ${ }^{21}$ or on the use of (+)-cincholoiponic acid $\{[(3 R, 4 S)$-3-ethylpiperidin-4yl]acetic acid $\}$ as the starting material. This acid is accessible by degradation of secologanin and cinchonine. ${ }^{22} \mathrm{~A}$ notable enantioselective synthesis of trans-(3-ethylpiperidin-4-yl)acetates, using an enantioselective intramolecular Michael addition as the key step, has been developed by Momose and co-workers. ${ }^{23}$
In this context, we described the efficient enantioselective synthesis of ethyl trans-[(3S,4S)-3-ethylpiperidin-4yl]acetate (13) and its corresponding lactam 14 from bicyclic lactam $\mathbf{9}$, which can be prepared in a single step by the stereoselective cyclocondensation of racemic formyl-containing diester 8 with $(R)$-phenylglycinol (Scheme 7). ${ }^{7 a, d}$ In this process, dynamic kinetic resolution and discrimination of the two diastereotopic acetate chains of racemic substrate $\mathbf{8}$ take place to stereoselectively afford bicyclic $\operatorname{lactam} 9$, in which the stereogenic centers next to the ethyl and acetate chains are generated with a well-defined configuration. Bicyclic lactam 9 is also accessible using an alternative procedure involving the stereoselective conjugate addition of the lithium salt of ethyl 1,3-dithiolane-2-carboxylate (11) to unsaturated lactam 10, easily accessible from 1A (Scheme 7). ${ }^{24}$ Treatment of the resulting dithiolane 12 with in situ generated nickel boride affords the above-mentioned lactam 9.
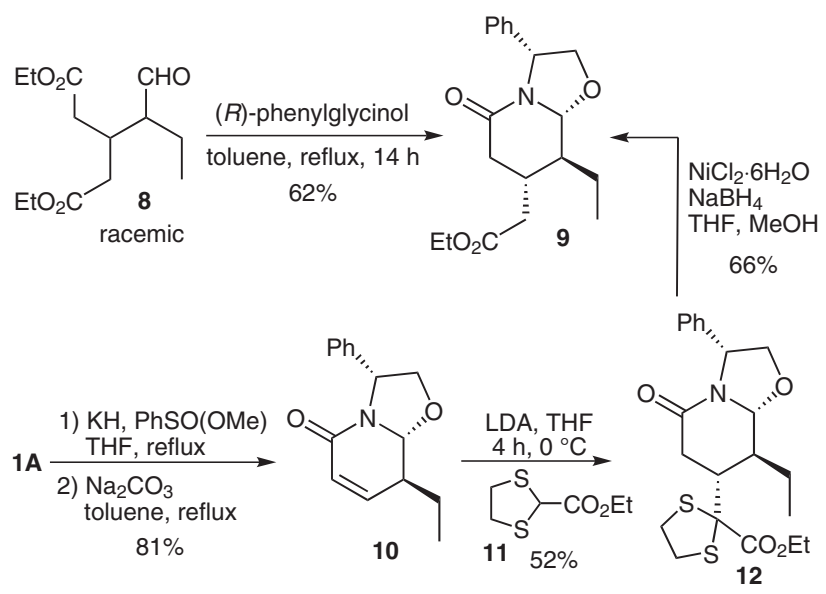

Scheme 7

Cleavage of the phenylethanol moiety of the chiral inductor of bicyclic lactam 9 to give 2-piperidone $\mathbf{1 4}$ was carried out by hydrogenolysis of the benzylic carbonnitrogen bond with calcium in liquid ammonia, followed by carbon-oxygen bond reduction of the resulting hemiaminal (Scheme 8). Alternatively, chemoselective reduction of 9 with borane-tetrahydrofuran complex, followed by debenzylation under catalytic hydrogenation conditions gave enantiopure ethyl trans-[(3S,4S)-3-ethylpiperidin-4-yl]acetate (13) in moderate yield (Scheme 8).

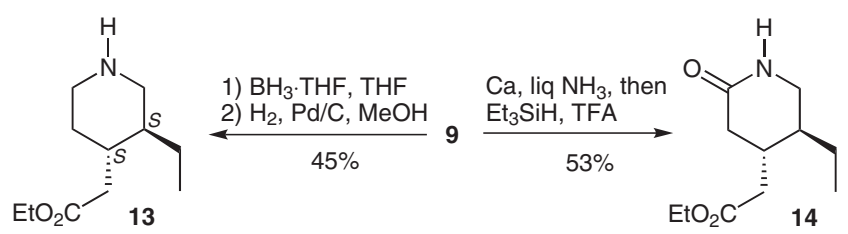

Scheme 8

A stereoselective procedure for the enantioselective synthesis of $c i s-[(3 S, 4 R)-3$-ethylpiperidin-4-yl]acetate derivatives 18 and 19 has also been developed. ${ }^{7 \mathrm{f}}$ The key step of the process is again a conjugate addition, but in this 
case of allylmagnesium bromide in the presence of copper(I) iodide (CuI) and trimethylsilyl chloride/lithium chloride to unsaturated lactam $\mathbf{1 5}$, which was prepared from 8-ethyl-substituted bicyclic derivative 1A, as depicted in Scheme 9. The addition of the allyl substituent to the activated double bond of $\mathbf{1 5}$ took place with high efficiency to give cis-7,8-disubstituted isomer 16. Conversion of the allyl substituent into an acetate chain by two successive oxidations and esterification of the resulting acid, followed by cleavage of the benzyloxycarbonyl substituent (Scheme 9), afforded the target cis-7,8-disubstituted lac$\operatorname{tam} 17$.

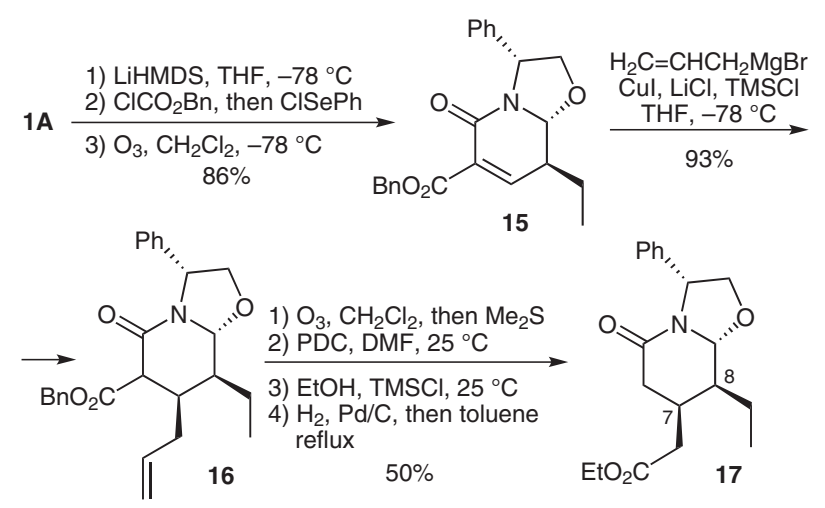

Scheme 9

Lactam 17 was converted into ethyl cis-[(3S,4R)-3-ethylpiperidin-4-yl]acetate (18) and ethyl cis-[(4R,5S)-5-ethyl-2-oxopiperidin-4-yl]acetate (19) following the abovementioned procedure for the preparation of 13 and 14, respectively, from trans-isomer 9 (Scheme 10).

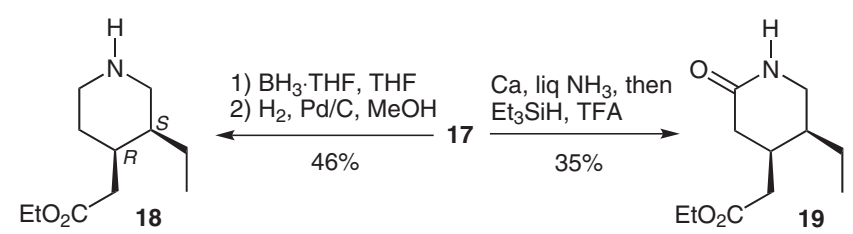

Scheme 10

The different stereochemical outcomes of the conjugate addition of the lithium salt of ethyl 1,3-dithiolane-2-carboxylate (11) to unsaturated lactam $\mathbf{1 0}$ and of a Grignard reagent in the presence of copper salts to unsaturated lactam 15 can be rationalized taking into account that, in the first case, the conjugate addition of a stabilized anion is a reversible process, stereoselectively affording the thermodynamically more stable trans-7,8-disubstituted isomer 12 (Scheme 11). The stereochemical course of the reaction and high stereoselectivity in the addition of an allyl organocuprate to $\mathbf{1 5}$ can be attributed to the stereoelectronically controlled axial attack ${ }^{25,26}$ of the nucleophile, resulting in cis-7,8-disubstituted isomer 16, and to the conformational rigidity of these bicyclic lactams (Scheme 11).

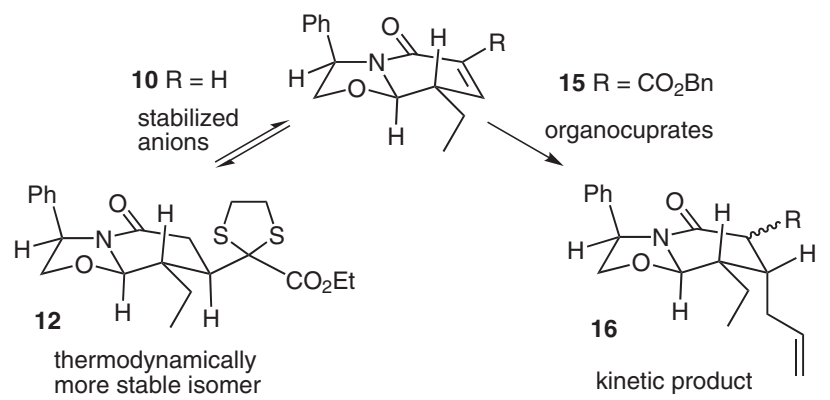

Scheme 11

(3-Ethylpiperidin-4-yl)acetates 13 and 18 and 2-piperidone derivatives 14 and 19 have been used in the synthesis of a number of alkaloids, such as emetine, tubulosine, ankorine, 9-demethylpsychotrine, dihydrocorynantheol, dihydrocorynantheine, and ophiorrhizine, among others, either in the racemic series or in enantiopure form. A notable contribution to this field was reported by Fujii and co-workers, who used the so-called 'lactim ether route' ${ }^{27}$

\subsubsection{Indole Alkaloids Related to Cleavamine and Quebrachamine}

The Aspidosperma group, the largest among the monoterpenoid indole alkaloids, displays a piperidine ring with a quaternary stereocenter $(\mathrm{C}-20)$ at the $\beta$-position embedded in a pentacyclic system. ${ }^{28}(+)$-Aspidospermidine constitutes a representative example of this group (Figure 4). The structural feature described above can also be found in eburnamine-vincamine-type alkaloids, such as (+)eburnamonine. The most simple group of the Aspidosper$m a$ alkaloids is exemplified by (-)-quebrachamine and its derivatives, which lack the C-7-C-21 bond. The tetracyclic framework of the alkaloid (-)-quebrachamine, char-

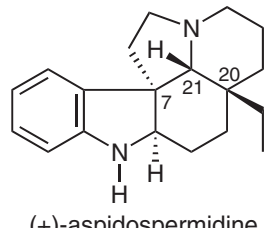

(+)-aspidospermidine<smiles>CC[C@@]1(CCC(=O)Nc2ccccc2-c2cccnc2)CCCn2cccc21</smiles><smiles>CCCc1cc2ccccc2[nH]1</smiles>

(-)-(20S)-dihydrocleavamine

Figure 4

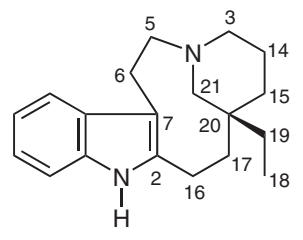

(-)-quebrachamine
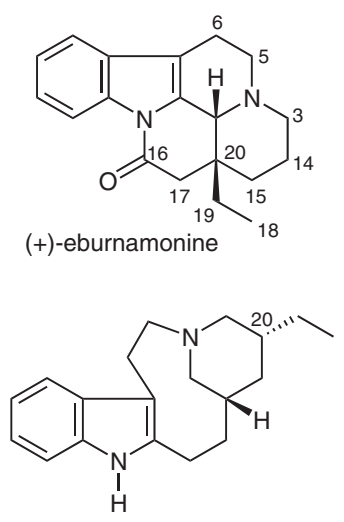

(+)-(20R)-dihydrocleavamine 
acterized by a central nine-membered ring, is shared by the alkaloids (-)-(20S)- and (+)-(20R)-dihydrocleavamine belonging to the Iboga skeletal type. ${ }^{29}$ However, because of their different biosynthetic pathways, the dihydrocleavamines have a 3,5-disubstituted piperidine ring, whereas (-)-quebrachamine has a 3,3-disubstituted piperidine subunit (Figure 4).

For the synthesis of (-)-quebrachamine (25) and the two C-20 diastereomeric dihydrocleavamines $\mathbf{4 0}$ and $\mathbf{4 1}$, we conceived a route based on the enantioselective preparation of an $(R)$-(3-ethylpiperidin-3-yl)acetate derivative and suitable trans-[(3R,5S)-5-ethylpiperidin-3-yl]- and cis-[(3R,5R)-5-ethylpiperidin-3-yl]acetates (Figure 5). Starting from these piperidines, the synthetic strategy involves, as key steps, (a) integration of the tryptamine moiety by acylation of the piperidine nitrogen with an indol3 -ylacetic acid derivative, (b) closure of the nine-membered ring by electrophilic cyclization at the indole 2-position, and (c) final reduction of the 2-acylindole and amide moieties.<smiles>CCC1(CC(=O)O)CCCNC1</smiles><smiles>CC[C@H]1CNC[C@@H](CC(=O)O)C1</smiles><smiles>CC[C@H]1CNC[C@H](CC(=O)O)C1</smiles><smiles></smiles>

a) nitrogen acylation

b) electrophilic cyclization (nine-membered ring formation) c) adjustment of the oxidation level

\section{Figure 5}

The enantioselective preparation of 3,3-disubstituted piperidines from simple chiral bicyclic lactams requires the sequential dialkylation of the corresponding enolate (Scheme 12). Our previous studies in this field ${ }^{30}$ led us to conclude that the stereoselectivity of the dialkylation reaction depends on the nature and order of introduction of the alkylating reagents. Thus, for the synthesis of methyl (3-ethylpiperidin-3-yl)acetate (22), which has the appropriate $R$ configuration for the synthesis of (-)-quebrachamine, we subjected the enolate of lactam ent-3, prepared from $(S)$-phenylglycinol, to sequential alkylation, first with allyl bromide and then with ethyl iodide. In this way, lactam 20 was obtained as a 91:9 mixture of diastereomers (the major isomer is depicted in Scheme 12) in $43 \%$ yield from lactam ent-3. It is worth mentioning that a change in the order of the addition of the alkylating reagents resulted in a decrease in stereoselectivity, affording a 70:30 mixture of the C-6 epimers of compound $\mathbf{2 0}$ in which the major isomer had the opposite $S$ configuration. Ruthenium oxidation of the carbon-carbon double bond of 20, followed by LAH reduction of the resulting acid, gave alcohol 21 in good yield. Hydrogenolysis of the $N$-benzylic substituent of $\mathbf{2 1}$ in the presence of di-tert-butyl dicarbonate, oxidation of the primary alcohol, and finally esterification of the resulting acid led to the target piperidine 22 .

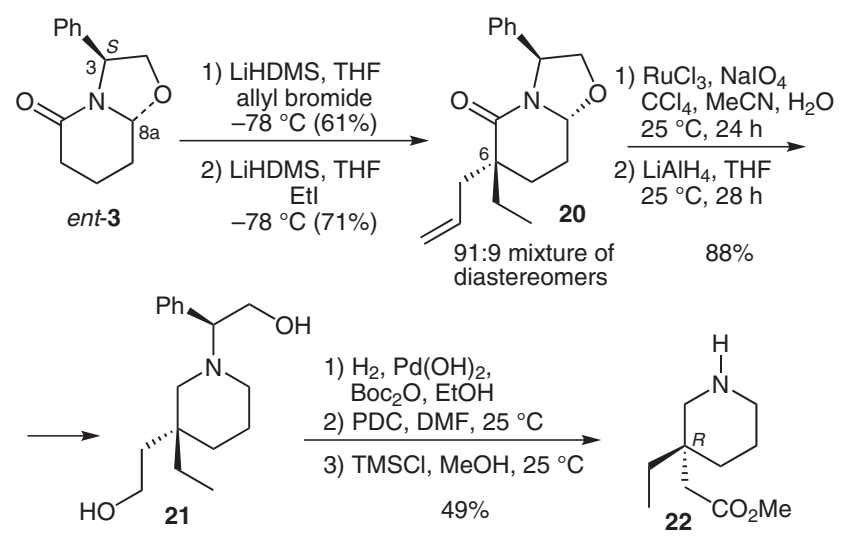

Scheme 12

With a procedure in hand for the preparation of enantiopure piperidine 22, we undertook the enantioselective synthesis of (-)-quebrachamine by reproducing the synthetic sequence used by F. E. Ziegler for the synthesis of this alkaloid in the racemic series ${ }^{31}$ (Scheme 13). The synthesis includes a remarkable transformation involving the closure of the nine-membered ring by poly(phosphoric acid) (PPA) treatment of acid $r a c-23$, which was reported to give rac-24 in $85 \%$ yield. Unfortunately, Ziegler and coworkers described that the subsequent reduction of the amide and 2-acylindole carbonyl moieties of rac-24 with LAH in refluxing dioxane afforded racemic quebrachamine $(r a c-25)$ in only $6 \%$ yield. Starting from enantiopure $R$-isomer $\mathbf{2 2}$, we prepared acid $\mathbf{2 3}$ by acylation of the secondary amine with the mixed anhydride derived from indol-3-ylacetic and pivalic acid, followed by saponification of the ester. Closure of the nine-membered ring
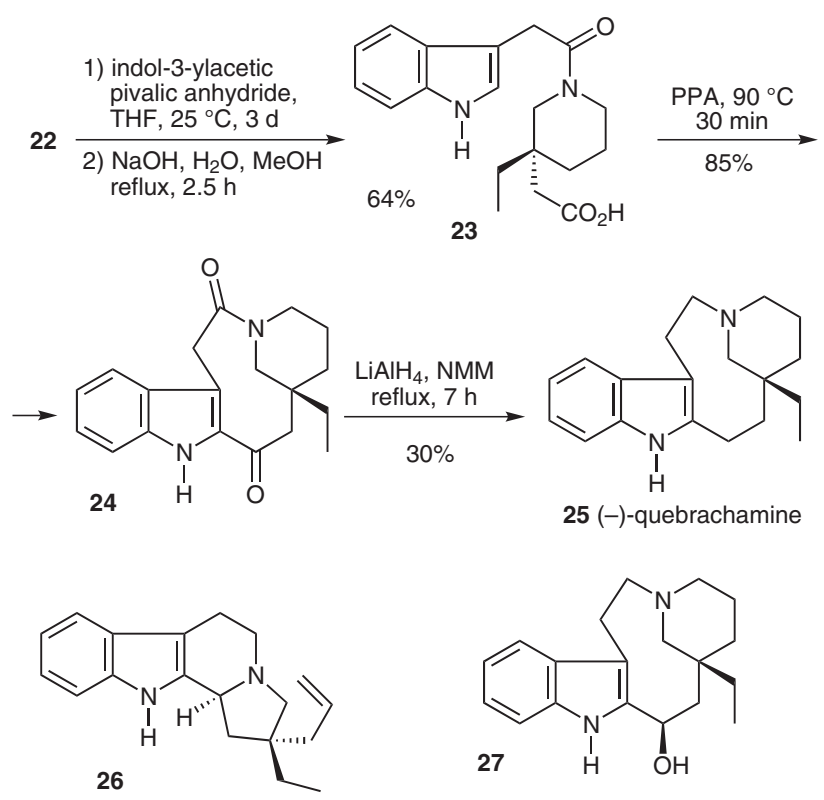

Scheme 13 
under the conditions reported by Ziegler and co-workers took place in high yield to give lactam 24 . However, when the reduction of lactam $\mathbf{2 4}$ was conducted with LAH in refluxing dioxane, only pyrrolo- $\beta$-carboline $\mathbf{2 6}$ was isolated (66\% yield), ${ }^{32}$ whereas in tetrahydrofuran (THF) at room temperature, alcohol 27 was formed in $87 \%$ yield as the only identifiable compound. To our delight, changing the solvent from THF to $N$-methylmorpholine (NMM) at reflux temperature allowed the isolation of the target alkaloid (-)-quebrachamine ${ }^{33}$ (25) in $30 \%$ yield, which represents a significant improvement on Ziegler's overall procedure (Scheme 13). ${ }^{30}$

For the enantioselective synthesis of the alkaloids (-)(20S)- (40) and (+)-(20R)-dihydrocleavamine (41), the initial preparation of trans-[(3R,5S)-5-ethylpiperidin-3yl]- 30 and cis-[(3R,5R)-5-ethylpiperidin-3-yl)acetate 35, respectively, was required. These diastereomeric compounds were synthesized by taking advantage of the stereoselectivity observed in the alkylation of enolates derived from ethyl-substituted bicyclic lactams 1A (Scheme 14) and $1 \mathbf{B}$ (Scheme 15). ${ }^{34}$ Thus, these C-8 and C-8a diastereomeric lactams underwent alkylation via the corresponding lithium enolates with the same facial selectivity using tertbutyl bromoacetate as the electrophile. Lactams $\mathbf{2 8}$ and $\mathbf{3 3}$ were formed with a trans and cis relative configuration, respectively, with respect to the C-6 and C-8 stereocenters. Although the stereoselectivity of the alkylation reaction was moderate (Schemes 14 and 15; only the major isomer is depicted), this procedure makes the enantioselective preparation of trans- and cis-3,5-disubstituted piperidines possible by choosing the appropriate $\mathrm{C}-8$ isomer of alkyl-substituted lactams 1A and 1B. Chemoselective borane reduction of the lactam carbonyl and oxazolidine ring moieties of compounds $\mathbf{2 8}$ and $\mathbf{3 3}$ afforded piperidines 29 and 34, respectively. Cleavage of the chiral inductor by hydrogenolysis gave piperidines $\mathbf{3 0}$ and 35, which were isolated as the hydrochloride and $N$-tertbutoxycarbonyl ( $N$-Boc) derivatives, respectively.

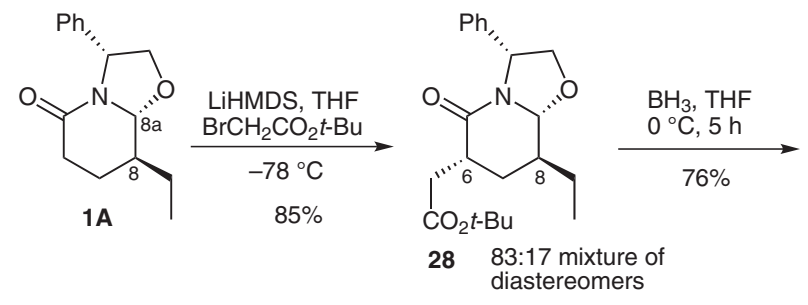

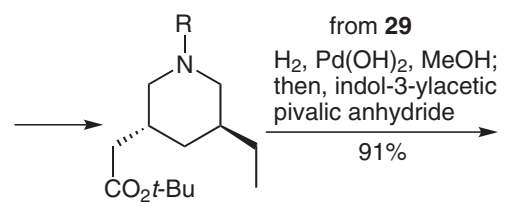

$\mathrm{H}_{2}, \mathrm{Pd}(\mathrm{OH})_{2}-29 \mathrm{R}=\mathrm{CHPhCH}_{2} \mathrm{OH}$ $\mathrm{MeOH}, \mathrm{HCl} \longrightarrow \mathbf{3 0} \cdot \mathrm{HCl} \mathrm{R}=\mathrm{H}$ $70 \%$

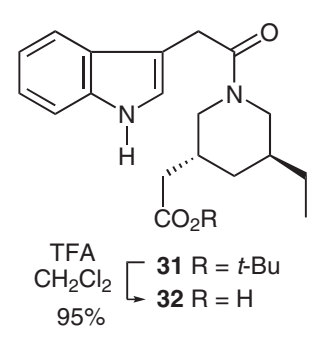

Scheme 14
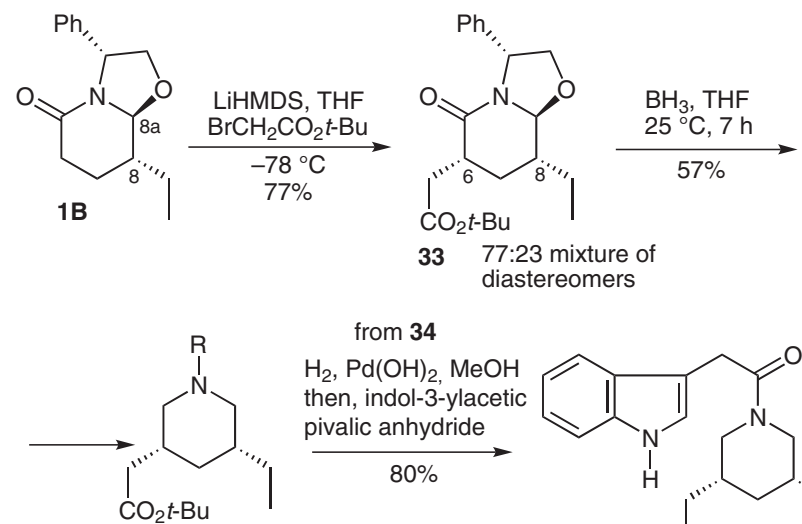

$\mathrm{H}_{2}, \mathrm{Pd}(\mathrm{OH})_{2}-34 \mathrm{R}=\mathrm{CHPhCH}_{2} \mathrm{OH}$

EtOAc, $\mathrm{Boc}_{2} \mathrm{O} \longrightarrow 35 \mathrm{R}=\mathrm{Boc}$

$71 \%$

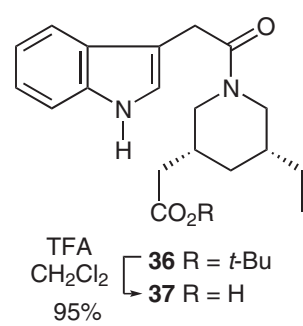

Scheme 15

The synthesis of alkaloids (-)-(20S)- (40) and (+)-(20R)dihydrocleavamine ${ }^{34,35}(\mathbf{4 1})$ using a procedure that parallels the one described for (-)-quebrachamine (25) required the preparation of amides 31 (Scheme 14) and 36 (Scheme 15), respectively. The formation of the amides was best accomplished in a one-pot reaction from alcohols 29 and 34 by adding indol-3-ylacetic pivalic anhydride to the mixture for the catalytic hydrogenation reaction. Subsequent treatment of amides $\mathbf{3 1}$ and $\mathbf{3 6}$ with trifluoroacetic acid (TFA) afforded acids $\mathbf{3 2}$ and 37, respectively, in excellent yield.

Closure of the nine-membered ring from trans-isomer 32 under the same reaction conditions used in the synthesis of (-)-quebrachamine (25) afforded tetracycle 38, although in lower yield (64\%, Scheme 16) than in the corresponding cyclization of $\mathbf{2 3}$ (cf. Scheme 13). Moreover, Danieli et al. ${ }^{36}$ described that all attempts to induce the cyclization of cis-isomer 37 using PPA failed, whereas the use of ethyl polyphosphate (PPE) in chloroform at $60{ }^{\circ} \mathrm{C}$ gave tetracycle $\mathbf{3 9}$, but in only $32 \%$ yield.

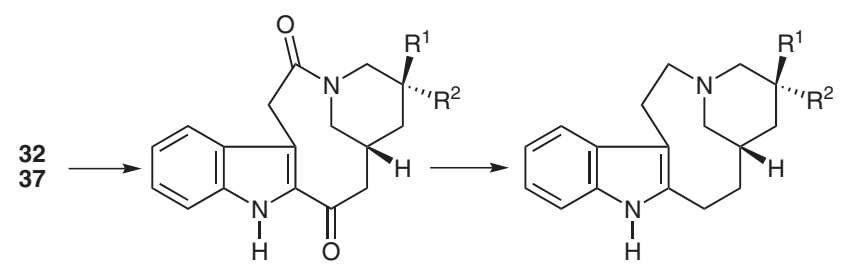
$38 R^{1}=E t, R^{2}=H$ $39 \mathrm{R}^{1}=\mathrm{H}, \mathrm{R}^{2}=\mathrm{Et}$<smiles>C=C(CC)C[C@H]1CC2c3[nH]c4ccccc4c3CCN2C1</smiles>

40 (-)-(20S)-dihydrocleavamine $41(+)-(20 R)$-dihydrocleavamine

cyclization from $32 \mathrm{PPA}, 90^{\circ} \mathrm{C}, 30 \mathrm{~min} 38(64 \%)$ from $37 \mathrm{PPE}, \mathrm{CHCl}_{3}, 60^{\circ} \mathrm{C} 39(32 \%)$

from $38 \mathrm{LiAlH}_{4}$, dioxane, reflux, $24 \mathrm{~h} 40$ (34\%) from $39 \mathrm{LiAlH}_{4}$, dioxane, reflux, 8 h $41(42 \%)$

Scheme 16 
The results observed in the above cyclization reactions of 23, 32, and 37 corroborate Ziegler's hypothesis ${ }^{31}$ that the actual acylating species in the intramolecular acylation step is the diacylammonium ion $\mathbf{F}$ (Figure 6), resulting from the interaction of the amide nitrogen with the transient acylium ion. This allows the cyclization to take place through a six-membered rather than a nine-membered transition state that would involve the direct attack of the acylium ion at the indole 2-position. The generation of reactive intermediate $\mathbf{F}$ requires the piperidine ring to adopt a conformation in which the acetate chain occupies an axial position. In the case of acids $\mathbf{2 3}$ and $\mathbf{3 2}$, the ethyl substituent in this conformation is equatorial. However, for compound $\mathbf{3 7}$, in which the ethyl and acetate chains are cis relative to one another, formation of species such as $\mathbf{F}$ requires the piperidine ring to adopt a less-favored conformation in which both substituents are axial.

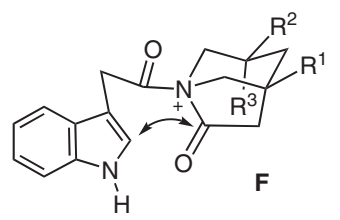

from $23 R^{1}=E t, R^{2}=R^{3}=H$ from $32 R^{1}=H, R^{2}=E t, R^{3}=H$ from $37 \mathrm{R}^{1}=\mathrm{R}^{2}=\mathrm{H}, \mathrm{R}^{3}=\mathrm{Et}$

Figure 6

Finally, LAH reduction of tetracycle $\mathbf{3 8}$ in refluxing dioxane satisfactorily afforded (-)-(20S)-dihydrocleavamine (40), although in moderate yield (34\%), accompanied by pyrrolo- $\beta$-carboline $\mathbf{4 2}$ in $17 \%$ yield (Scheme 16). Similarly, Danieli et al. ${ }^{36}$ reported that the LAH reduction of isomer 39 afforded (+)-(20R)-dihydrocleavamine ${ }^{37}$ under the same conditions in $42 \%$ yield.

The modest yields in the reduction of tetracycles $\mathbf{3 8}$ and 39 with LAH in refluxing dioxane and the different behavior of these compounds compared with that of $\mathbf{2 4}$ under the same conditions could be accounted for by considering the formation of quaternary ammonium salt G (Scheme 17). This intermediate, generated through a cyclization of the partially reduced 2-acylindole moiety, can undergo two competitive reactions: reduction of the $\mathrm{C}-16-\mathrm{N}$ bond by hydride attack to give $\mathbf{2 5}, \mathbf{4 0}$, or $\mathbf{4 1}$, or a Hofmann-type elimination to give pyrrolo- $\beta$-carbolines $\mathbf{2 6}$ or $\mathbf{4 2}$. Starting from tetracycle $\mathbf{2 4}$, the $\beta$-elimination process involving the corresponding salt $\mathbf{G}\left(\mathrm{R}^{1}=\mathrm{Et}, \mathrm{R}^{2}=\right.$ $\mathrm{H}$ ) is favored by Hofmann's rule compared with the same reaction of salt $\mathbf{G}$ generated from $\mathbf{3 8}\left(\mathrm{R}^{1}=\mathrm{H}, \mathrm{R}^{2}=\mathrm{Et}\right)$ (Scheme 17). The presence of an ethyl substituent on the quaternary center of intermediate ammonium salt $\mathbf{G}$ formed from $24\left(R^{1}=E t, R^{2}=H\right)$ hinders the approach of the hydride to the reactive $\mathrm{C}-16$ position. As a consequence, when the reaction is conducted in dioxane, only pyrrolo- $\beta$-carboline $\mathbf{2 6}$ is observed. However, when the solvent is changed to NMM in the LAH reduction of $\mathbf{2 4}$, this tertiary amine competes with the nitrogen atom of the piperidine ring, partly avoiding the cyclization to ammo-

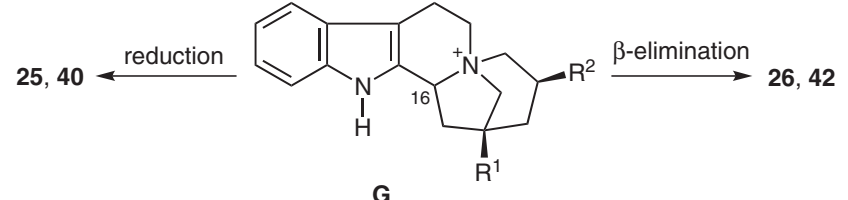

from $24, R^{1}=E t, R^{2}=H$

from $38, R^{1}=H, R^{2}=E t$

Scheme 17

nium salt G. The resulting 'external' ammonium salt is reduced by hydride attack affording (-)-quebrachamine (25).

\subsection{Uleine and Strychnos Alkaloids}

The uleine alkaloids constitute a small group of indole alkaloids lacking the tryptaminic two-carbon link between the indole 3-position (C-7 with respect to biogenetic numbering) and the nitrogen atom of the piperidine ring. ${ }^{38}$ The fundamental tetracyclic framework of these alkaloids consists of an indole nucleus fused to a 2-azabicyclo[3.3.1]nonane (Figure 7).

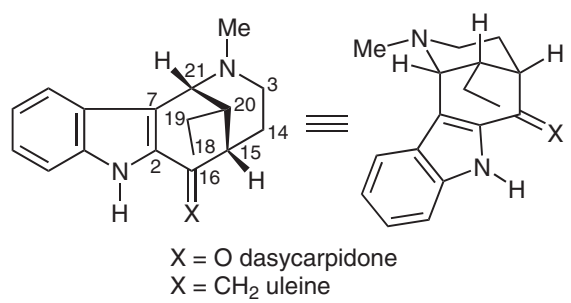

Figure 7

Starting from chiral phenylglycinol-derived bicyclic lactams, access to the bridged tetracyclic system of these natural products can be achieved by the conjugate addition of a carbon nucleophile next to the indole 2-position to unsaturated ethyl-substituted lactam 10, followed by an intramolecular amidoalkylation reaction (Figure 8). As can be observed in Figure 7, these alkaloids have three stereogenic centers, all on the piperidine ring, with a cis relative configuration. Thus, to ensure the correct stereochemistry for the synthesis of uleine and dasycarpidone, the conjugate addition of the nucleophile to unsaturated lactam $\mathbf{1 0}$ should afford the cis-isomer with respect to the ethyl substituent, and the configuration of the C-8 chiral center of 10 bearing this substituent must be $S$ (Figure 8 ).

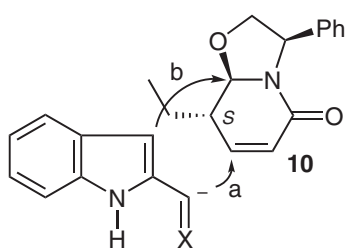

a) stereoselective conjugate addition $\left(\mathrm{C}_{15}-\mathrm{C}_{16}\right.$ bond $)$

b) intramolecular amidoalkylation $\left(\mathrm{C}_{7}-\mathrm{C}_{21}\right.$ bond $)$

Figure 8 
The required cis-isomer $\mathbf{4 4}$ was obtained by the conjugate addition of an excess amount ( 2 equiv) of the dilithium salt of 2-(1,3-dithian-2-yl)-1H-indole to unsaturated lactam 10 (Scheme 18). After stirring the reaction mixture at $-78{ }^{\circ} \mathrm{C}$ in THF for 12 hours, a 4:1 mixture of isomers $\mathbf{4 4}$ and $\mathbf{4 3}$ was obtained in $90 \%$ yield. ${ }^{24}$ The observed stereoselectivity can be accounted for by considering that, under kinetic conditions, the stereoelectronically controlled cisisomer is formed as the major product. However, when the conjugate addition of the dianion derived from 2-(1,3dithian-2-yl)- $1 H$-indole (1.2 equiv) was carried out at room temperature and stirring was continued for 16 hours, enantiopure trans-isomer $\mathbf{4 3}$ was stereoselectively formed as the only identifiable product in excellent yield (93\%). ${ }^{39}$ This result shows that, under these conditions, the equilibration of the initially formed kinetic product, cis-isomer $\mathbf{4 4}$, to the thermodynamic product, trans-isomer $\mathbf{4 3}$, occurs.

Conversion of $c i s$-substituted lactam $\mathbf{4 4}$ into the target tetracyclic alkaloids of the uleine group required, as the key steps, the closure of the carbocyclic ring and the removal of the chiral inductor. Treatment of compound $\mathbf{4 4}$ with sodium in liquid ammonia brought about both the desulfurization of the dithioacetal and the cleavage of the benzylic carbon-nitrogen bond to give a hydroxy-containing lactam, which was subjected to electrophilic cyclization by treatment with titanium(IV) chloride $\left(\mathrm{TiCl}_{4}\right)$ leading to tetracycle $\mathbf{4 5}$ in 35\% yield from lactam 44 (Scheme 19). Borane reduction of the lactam carbonyl moiety of $\mathbf{4 5}$, followed by acylation of the resulting secondary amine with benzyl chloroformate afforded carbamate $\mathbf{4 6}$ in $\mathbf{4 0 \%}$ yield. ${ }^{24,40}$ Compound $\mathbf{4 6}$ has been previously converted into (+)-dasycarpidone (47) by oxidation with pyridinium dichromate on Celite and tert-butyl hydroperoxide, followed by cleavage of the $\mathrm{N}$-benzyloxycarbonyl substituent and in situ methylation by hydrogenolysis in the presence of formaldehyde. ${ }^{41}$ Taking into account previous correlations, the above procedure also represents a formal synthesis of (+)-uleine, (-)-dasycarpidol, and (-)-17-hydroxydihydrouleine. ${ }^{42}$
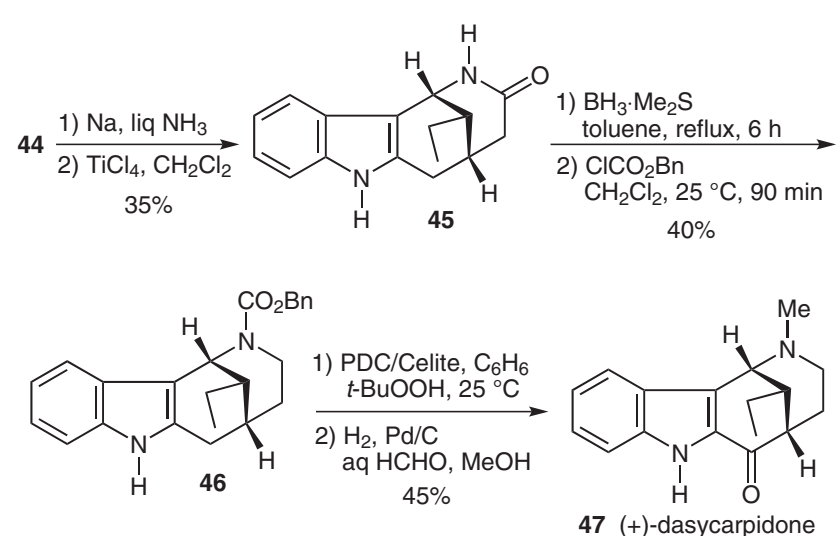

Scheme 19

cis-2-[(3-Ethylpiperidin-4-yl)methyl]indole derivatives constitute key intermediates for the synthesis not only of alkaloids of the uleine group, but also of pentacyclic Strychnos indole alkaloids, such as (-)-tubifoline (51) and (-)-19,20-dihydroakuammicine (Scheme 20). Because no enantioselective synthesis of these synthetic intermediates had been previously described, we decided to undertake the conversion of lactam $\mathbf{4 4}$ into piperidine $\mathbf{4 8}$. Thus, reductive desulfurization of dithioacetal $\mathbf{4 4}$ with in situ generated nickel boride, followed by reduction of the lactam carbonyl moiety with simultaneous reductive cleavage of the oxazolidine ring, and finally hydrogenolysis of the resulting $N$-benzylic substituent afforded compound $\mathbf{4 8}$ in $55 \%$ yield from lactam $\mathbf{4 4} .{ }^{39}$ Conversion of racemic (indol-2-ylmethyl)piperidine rac-48 into the alkaloid tubifoline was described in 2008 by Ishikura et al. ${ }^{43}$ following a procedure previously reported by $\mathrm{Wu}$ and Snieckus ${ }^{44}$ for the synthesis of tetracycle rac-50. Acylation of piperidine rac-48 with chloroacetyl chloride followed by photocyclization of the resulting chloroacetamide using a lowpressure mercury lamp afforded nine-membered lactam rac-49. Subsequent reduction of the amide carbonyl moiety of rac-49 with LAH gave tetracyclic amine rac-50. This compound has been prepared in enantiopure form in our laboratories following a similar synthetic route in the<smiles>CCC1C=CC(=O)N2[C@H](c3ccccc3)CO[C@H]12</smiles>

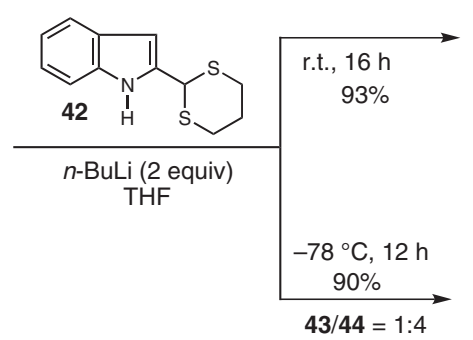<smiles></smiles><smiles></smiles>

44

Scheme 18 
context of our studies on the synthesis of Strychnos alkaloids. ${ }^{45}$ In our hands, the oxidative transannular cyclization of (-)-50 led to pentacyclic alkaloid (-)-tubifoline (51), which was subsequently transformed into (-)-tubifolidine and (-)-19,20-dihydroakuammicine.
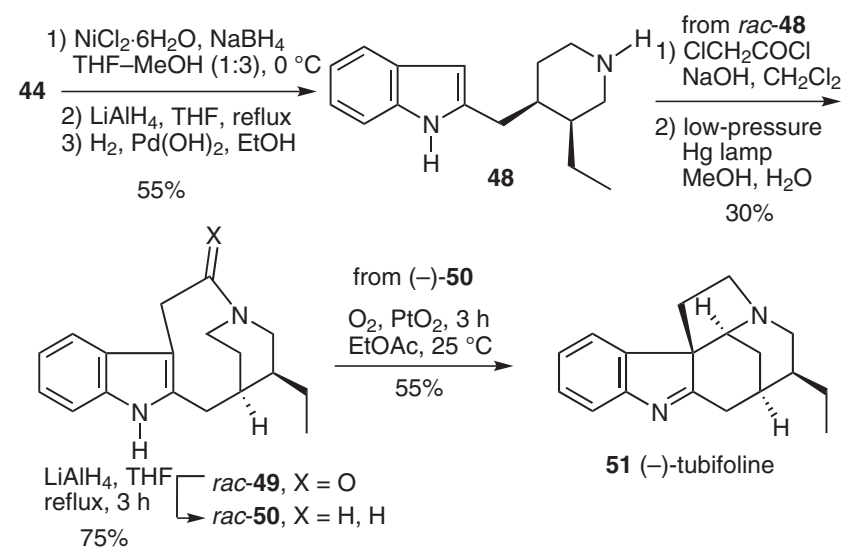

51 (-)-tubifoline

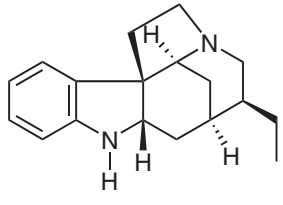

(-)-tubifolidine

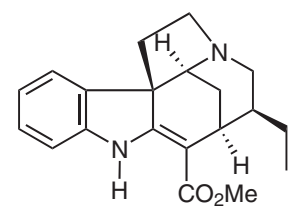

(-)-19,20-dihydroakuammicine

Scheme 20

\subsection{The Ervatamine-Silicine Group}

The ervatamine-silicine group of alkaloids ${ }^{46}$ display an unusual tetracyclic skeleton in which the carbon atoms of the tryptamine unit, C-5 and C-6, are embedded in the piperidine ring and a seven-membered carbocycle, respectively, instead of forming a two-carbon bridge between the indole 3-position and the basic nitrogen (Figure 9). Most of the alkaloids of the silicine group differ in their relative stereochemistry at $\mathrm{C}-16$ and $\mathrm{C}-20$ and oxidation level at $\mathrm{C}-6$. The ervatamine alkaloids have an additional methoxycarbonyl substituent at the $\mathrm{C}-16$ position of the tetracyclic system.

The synthetic route we have developed for the synthesis of ervatamine-silicine alkaloids ${ }^{47}$ relies on the closure of

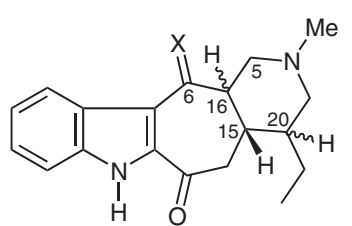

$\frac{\mathrm{X}}{\mathrm{H}, \mathrm{H}-16 \mathrm{H}-20}$ silicine

$\mathrm{H}, \mathrm{H} \quad \alpha \quad \beta \quad$ 16-episilicine

$\mathrm{H}, \mathrm{H} \quad \beta \quad \alpha \quad$ 20-episilicine

$\mathrm{H}, \mathrm{H} \quad \alpha \quad \alpha \quad 16,20$-episilicine

$0 \quad \beta \quad \beta \quad 6$-oxosilicine

O $\alpha \quad \beta$ 6-oxo-16-episilicine

O $\alpha \quad \alpha$ 6-oxo-16,20-episilicine

Figure 9 the seven-membered ring by ring-closing metathesis (RCM) in the last steps of the synthesis and takes advantage of our experience in the stereocontrolled introduction of substituents on the piperidine ring of phenylglycinolderived bicyclic lactams. Thus, starting from an unsaturated lactam derived from $\mathbf{1 B}$, with an $R$ configuration at the stereocenter next to the ethyl substituent (corresponding to C-20 of the alkaloids), the key steps of the synthesis are (a) the conjugate addition of a vinyl residue, (b) the stereoselective alkylation of an enolate for the introduction of the (2-vinylindol-3-yl)methyl fragment, and (c) RCM for the closure of the seven-membered ring (Figure 10).

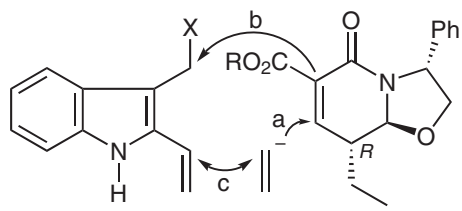

a) stereoselective conjugate addition (C-15 stereocenter)

b) stereoselective alkylation (C-16 stereocenter)

c) RCM: closure of the sevenmembered ring

Figure 10

Unsaturated lactam 52, easily available from bicyclic lactam 1B, underwent conjugate addition of vinylmagnesium bromide in the presence of $\mathrm{CuI}$ with the expected facial selectivity $^{6 \mathrm{c}, 7 \mathrm{~b}}$ to stereoselectively give compound $\mathbf{5 3}$ in excellent yield. The subsequent alkylation of lactam $\mathbf{5 3}$ with indol-3-ylmethyl bromide $\mathbf{5 4}$, followed by Wittig methylenation, afforded desired derivative $\mathbf{5 5}$ as a single stereoisomer (Scheme 21). At this point, it is worth mentioning that, in previous studies, all attempts to close the carbocyclic ring of the ervitsine-silicine alkaloids by the RCM reaction of related divinyl derivatives failed to lead to the expected compound, with an intramolecular DielsAlder process taking place instead. ${ }^{47}$ This result was explained by conformational restrictions attributable to the steric hindrance caused by the carboxylate moiety on the quaternary carbon. For this reason, the Boc group of (indol-3-ylmethyl)-substituted lactam 55 was stereoselectively removed by treatment with TFA and heating in toluene. The subsequent RCM reaction of the resulting compound using the second-generation Grubbs catalyst, followed by hydrogenation of the carbon-carbon double bond, led to desired compound 56, which bears the tetracyclic skeleton of the ervatamine-silicine alkaloids. Removal of the chiral inductor and the protecting group of the indole moiety of compound $\mathbf{5 6}$ was accomplished by simultaneous reduction of the amide and oxazolidine ring, followed by cleavage of the phenylsulfonyl group by treatment with magnesium turnings in methanol, and finally hydrogenolysis of the $N$-benzylic substituent with in situ protection of the resulting secondary amine. Chemoselective oxidation of the methylene carbon next to the indole 2-position of the resulting tetracycle 57 with diiodine pentoxide, followed by removal of the Boc protecting group and methylation of the resulting secondary amine, gave alkaloid (-)-16-episilicine (58). ${ }^{48,49}$ 

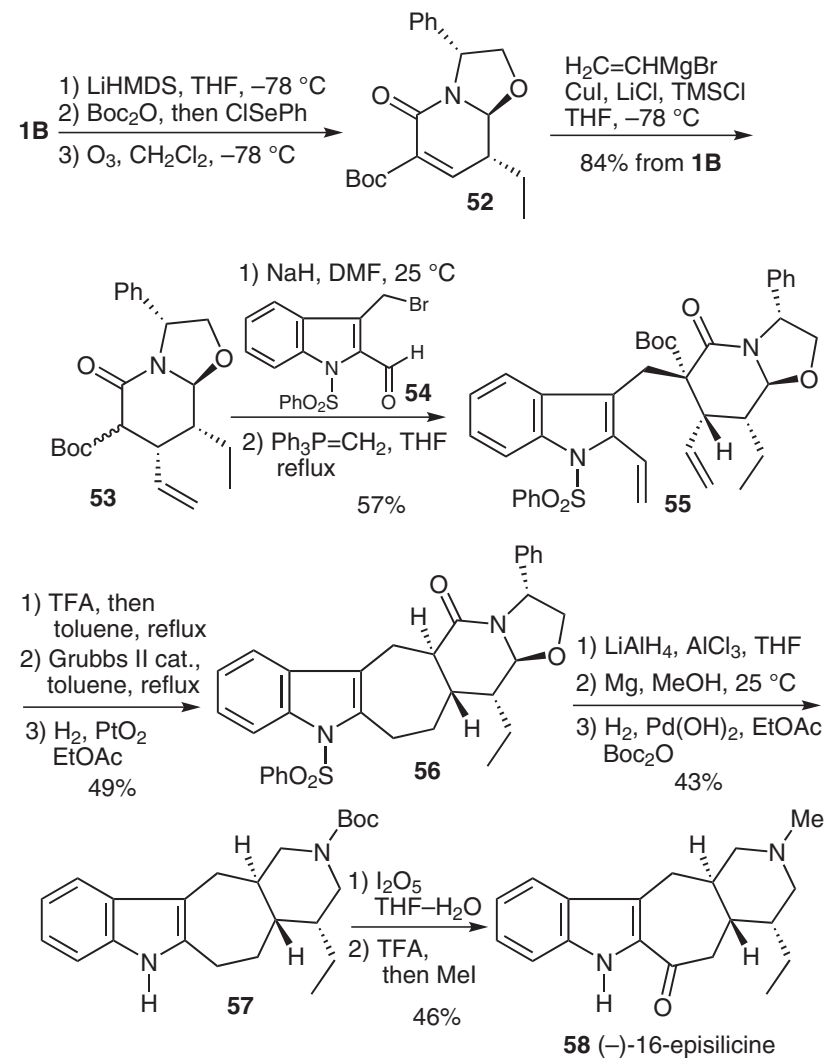

Scheme 21

\section{Indolo[2,3-a $]$ quinolizidines from $(S)$-Tryp- tophanol-Derived Lactams}

As an extension of our work on the use of chiral amino alcohol derived bicyclic lactams for the enantioselective synthesis of natural products, we decided to explore the use of $(S)$-tryptophanol-derived bicyclic lactams for the synthesis of indole alkaloids. ${ }^{50}$ In this case, the chiral amino alcohol would not only be a source of chirality, as in the case of phenylglycinol-derived lactams, but would also incorporate the tryptamine moiety present in many indole alkaloids. With this purpose in mind, unsubstituted lactam 60 and the C-7 and/or C-8 substituted derivatives 61 to 64 were stereoselectively prepared in good yields by the cyclocondensation reaction of formyl-containing ester derivatives 59 and $(S)$-tryptophanol (Scheme 22). As in the above cyclocondensation reactions using phenylglycinol, minor amounts of a second diastereomer was also isolated in all cases. ${ }^{51}$

Taking advantage of the functionalization present in lactams 60 to 64, the indole ring can undergo electrophilic cyclization at both $\alpha$-positions of the piperidine ring present in the bicyclic system (Figure 11), either by a Bischler-Napieralski reaction (via path a) or by intramolecular $\alpha$-amidoalkylation (via path $\mathrm{b}$ ), affording regioisomeric indolo[2,3-a]quinolizidine derivatives. Thus, starting from C-8 substituted lactams 61, 62, and 64, Bischler-Napieralski-type reactions would afford C-3 substi-

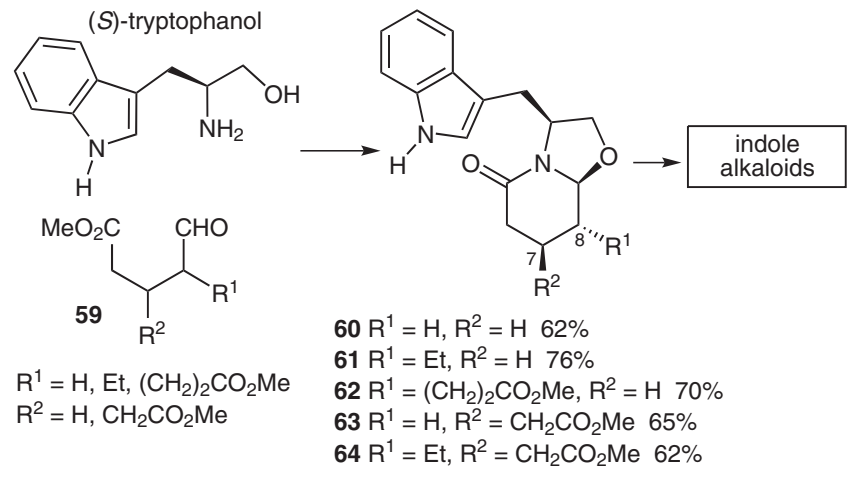

Scheme 22

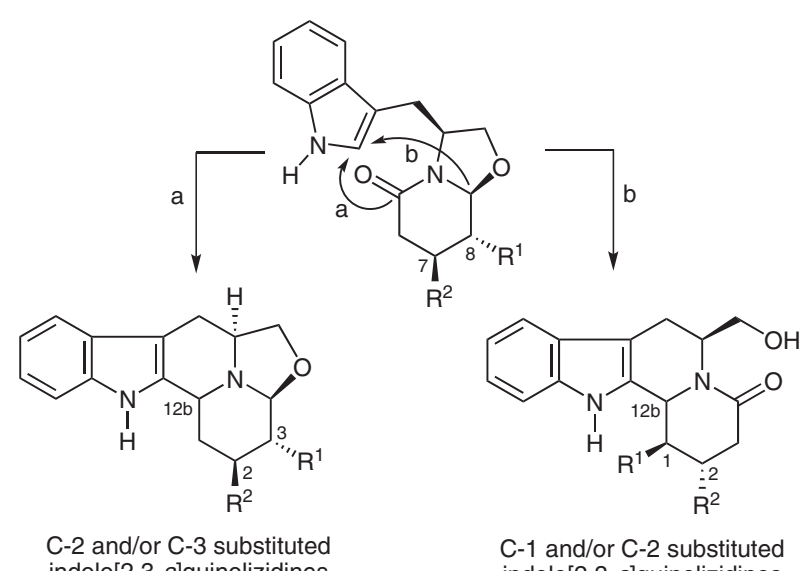

indolo[2,3-a]quinolizidines indolo[2,3-a]quinolizidines

Figure 11

tuted indolo[2,3- $a$ ]quinolizidine derivatives, whereas amidoalkylation processes would give C-1 substituted tetracyclic systems.

\subsection{Indolo[2,3- $a$ ]quinolizidines and Analogues by Intramolecular Amidoalkylation Reac- tions: Synthesis of $(R)-(+)$-Deplancheine and $(R)$-(+)-Harmicine}

Treatment of oxazolopiperidone lactams under acidic conditions generates an $N$-acyliminium ion that, in the case of $(S)$-tryptophanol-derived lactams, can undergo an electrophilic cyclization at the indole 2-position affording indolo[2,3-a]quinolizidines. This tetracyclic scaffold is present in many indole alkaloids of the Corynanthe group. Thus, the $\mathrm{TiCl}_{4}$-promoted cyclization of unsubstituted $(S)$-tryptophanol-derived lactam $\mathbf{6 0}$ was described by Allin et al., ${ }^{52}$ affording a 5:2 mixture of indolo[2,3-a]quinolizidines $65 \mathrm{~A}$ and $65 \mathrm{~B}$, which are diastereomers at the C$12 \mathrm{~b}$ stereocenter generated in the reaction (Scheme 23). The use of hydrogen chloride $(\mathrm{HCl})$ in the intramolecular amidoalkylation reaction, however, led to the single isomer $\mathbf{6 5 A}$, with a trans $\mathrm{H}-6 / \mathrm{H}-12 \mathrm{~b}$ relative configuration, in excellent yield. ${ }^{53}$ This stereoselectivity was rationalized by considering that the cyclization takes place based on the conformation of the exocyclic carbon-nitrogen bond in which the $\mathrm{A}^{1,3}$-type interaction of the carbon sub- 
stituents on the stereogenic center of the tryptophanol moiety and the lactam carbonyl functionality is minimized. As a consequence, the indole nucleus attacks the iminium salt from the $s i$-face, stereoselectively affording indoloquinolizidine $\mathbf{6 5} \mathrm{A} .{ }^{51 \mathrm{~b}, 54}$
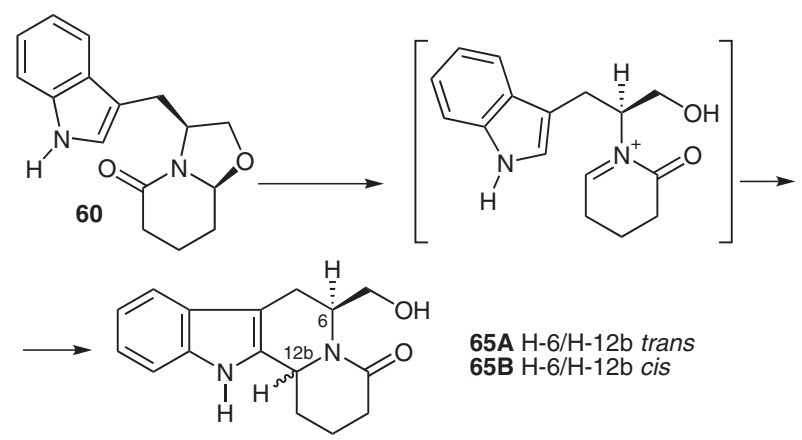
65A H-6/H-12b trans
65B H-6/H-12b cis

$\mathrm{TiCl}_{4}, \mathrm{CH}_{2} \mathrm{Cl}_{2},-78{ }^{\circ} \mathrm{C}$ to r.t., $20 \mathrm{~h} 65 \mathrm{~A} / 65 \mathrm{~B}=5: 2 ; 54 \%$ $2 \mathrm{M} \mathrm{HCl}$, EtOH, r.t., $20 \mathrm{~h}$ 65A (single isomer); $95 \%$

Scheme 23

When the analogous ethyl-substituted lactam 61 was subjected to treatment with boron trifluoride-diethyl ether complex in dichloromethane at reflux, we observed the formation of the $\mathrm{H}-6 / \mathrm{H}-12 \mathrm{~b}$ cis-isomer $\mathbf{6 6 B}$ with good stereoselectivity, whereas with $\mathrm{HCl}$ at room temperature, the H-6/H-12b trans-isomer 66A was the major component of the isomeric mixture (Scheme 24), ${ }^{51 \mathrm{~b}}$ in accordance with Allin's results. Thus, by the appropriate selection of the acidic reagent used to promote the intramolecular amidoalkylation of lactam 61, C-12b diastereomeric indolo[2,3- $a]$ quinolizidine 66A or 66B can be obtained.

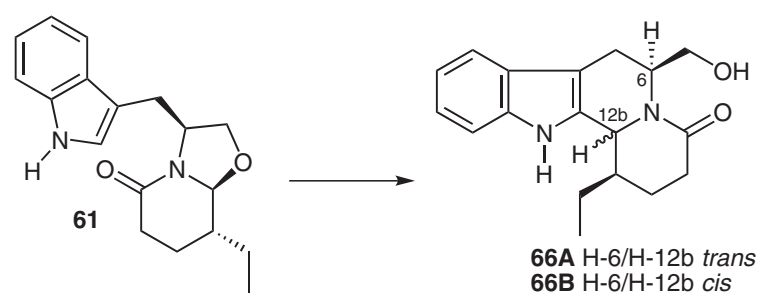

$\mathrm{BF}_{3} \cdot \mathrm{OEt}_{2}, \mathrm{CH}_{2} \mathrm{Cl}_{2}$, reflux, $24 \mathrm{~h}$, then $\mathrm{KOH} 66 \mathrm{~A} / 66 \mathrm{~B}=18: 82 ; 74 \%$ $1.2 \mathrm{~N} \mathrm{HCl}$, EtOH, r.t., 24 h 66A/66B = 86:14; 95\% yield

\section{Scheme 24}

In a related study, Allin et al. reported that the partial reduction of the $(S)$-tryptophanol-derived succinimide $\mathbf{6 7}$ under Speckamp conditions afforded the corresponding tetrahydropyrrolo- $\beta$-carboline as a mixture of the $\mathrm{H}-5 / \mathrm{H}-$ $11 \mathrm{~b}$ trans- and cis-isomers $68 \mathrm{~A}$ and $68 \mathrm{~B}$, respectively, in a 9:1 ratio (Scheme 25). ${ }^{55}$ The reaction takes place through the cyclization of an intermediate $N$-acyliminium salt, analogous to that generated by the acidic treatment of bicyclic lactams 60 and 61 in the aforementioned cyclizations to give indoloquinolizidines $65 \mathrm{~A} / 65 \mathrm{~B}$ and $66 \mathrm{~A} / 66 \mathrm{~B}$, respectively.
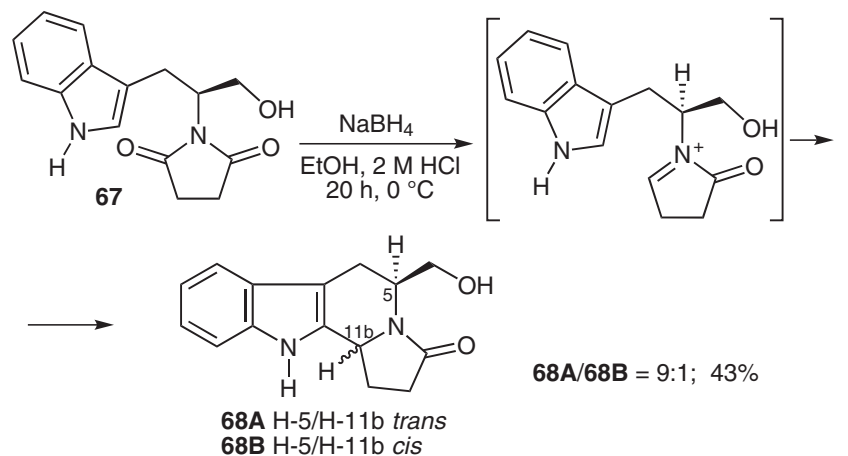

$68 \mathrm{~A} / 68 \mathrm{~B}=9: 1 ; 43 \%$ 68A $\mathrm{H}-5 / \mathrm{H}-11 \mathrm{~b}$ tran
$68 \mathrm{~B}-5 / \mathrm{H}-11 \mathrm{~b}$ cis

Scheme 25

Compound 65A was converted into $(R)-(+)$-deplancheine (72), ${ }^{56}$ an indole alkaloid isolated from the New Caledonian plant Alstonia deplanchei lacking the two- or three-carbon chain present in most Corynanthe alkaloids at the $\mathrm{C}-15$ position. The key transformations are the removal of the hydroxymethyl appendage and the incorporation of the $(E)$-ethylidene side chain. The former was accomplished by oxidation of alcohol $65 \mathrm{~A}$ to give carboxylic acid 69 followed by the formation of the corresponding acyl selenide, which was then subjected to a tinmediated radical decarbonylation to give compound $\mathbf{7 0}$ (Scheme 26). Treatment of the lithium enolate of lactam 70 with acetaldehyde, followed by mesylation of the resulting alcohol and 1,5-diazabicyclo[4.3.0]non-5-ene-induced $\beta$-elimination of the mesylate, regio- and stereoselectively afforded desired product $\mathbf{7 1}$ bearing the (E)-ethylidene substituent. Finally, removal of the $N$-Boc protecting group of tetracycle $\mathbf{7 1}$ and lactam reduction gave the alkaloid $(R)-(+)$-deplancheine (72).
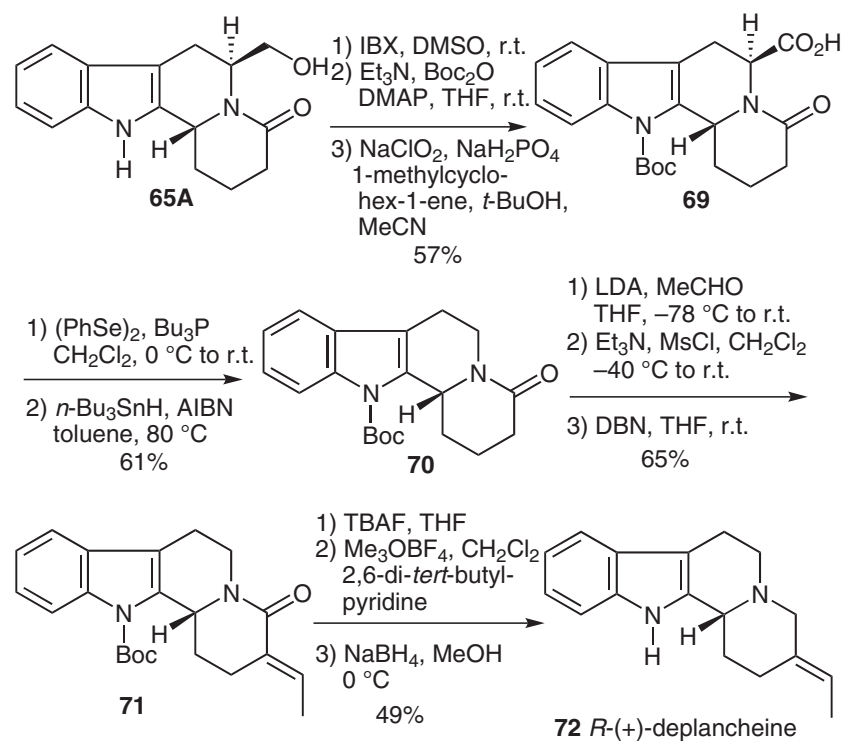

Scheme 26

Following a similar procedure for the removal of the hydroxymethyl chain, compound $\mathbf{6 8 \mathbf { A }}$ was converted into tetrahydropyrrolo- $\beta$-carboline 74. Subsequent deprotection by removal of the $N$-Boc group and LAH reduction 
afforded the indole alkaloid (+)-harmicine (75) (Scheme 27), ${ }^{55}$ which is isolated from the leaf extracts of the Malasian plant Kopsia griffithii.
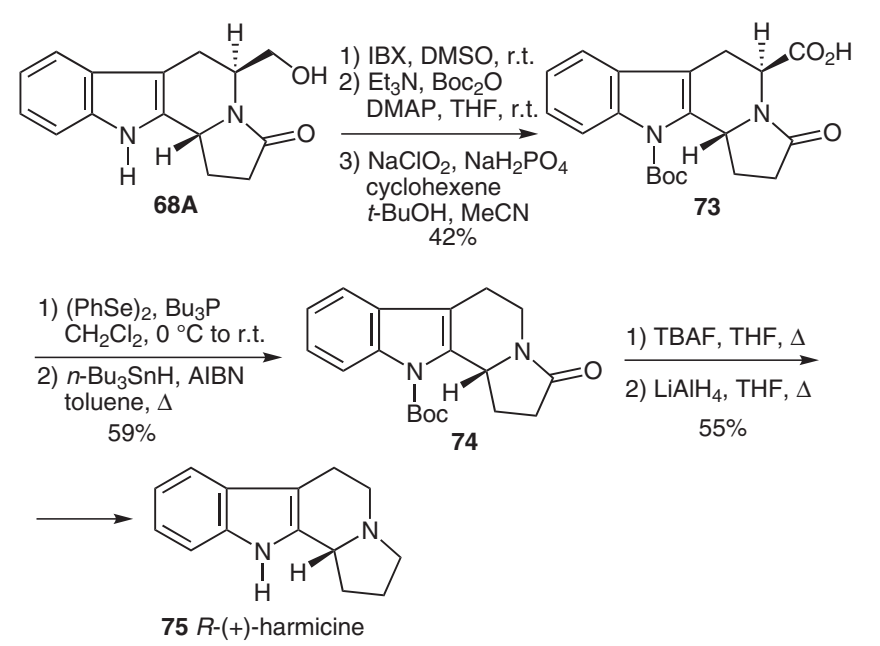

Scheme 27

\subsection{Indolo[2,3- $a]$ quinolizidines by a Modified Bischler-Napieralski Reaction: Formal Synthesis of (+)-Dihydrocorynantheine and (-)-Dihydrocorynantheol}

The use of C-8 substituted tryptophanol-derived bicyclic lactams for the alternative enantioselective synthesis of indole alkaloids requires the cyclization at the indole 2position to take place regioselectively from the lactam carbonyl moiety (see Figure 11, path a). In this way, indo$\operatorname{lo}[2,3-a]$ quinolizidines bearing a carbon substituent at the $\mathrm{C}-3$ position of the core tetracyclic system (corresponding to C-20 in the biogenetic numbering of the Corynanthe alkaloids, see Scheme 2) can be formed. However, in preliminary attempts, when lactam $\mathbf{6 1}$ was subjected to Bischler-Napieralski conditions, instead of the desired C3 substituted indolo[2,3- $a$ ]quinolizidine, a mixture of compounds 66A and 76 resulting from intramolecular amidoalkylation (see Figure 11, path b) was formed

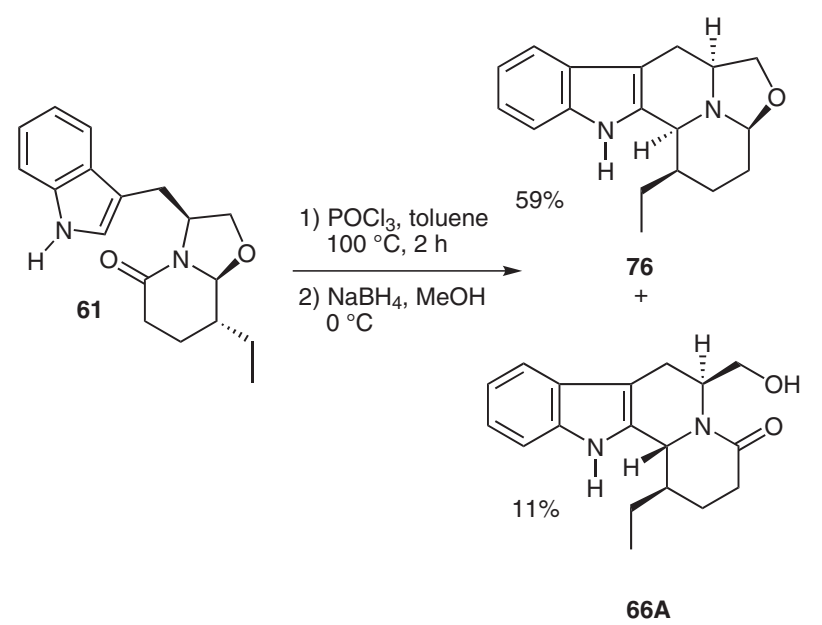

Scheme 28
(Scheme 28). The formation of $\mathbf{7 6}$ also involved the partial reduction of the lactam carbonyl moiety with closure of the oxazolidine ring. Similarly, all attempts to reduce the carbon-oxygen bond of $\mathbf{6 1}$ using triethylsilane in the presence of a variety of Lewis acids failed and, in some cases, compounds resulting from an intramolecular amidoalkylation reaction were also formed.

In view of the above results, it was evident that the proposed cyclization had to be carried out under neutral or basic conditions to avoid the competitive acid-promoted amidoalkylation process. Alkylation of thioamide 77, obtained by treatment of lactam $\mathbf{6 1}$ with Lawesson's reagent, using benzyl bromide generated (benzylsulfanyl)-substituted iminium ion $\mathbf{H}$, which can be considered as a sulfur analogue of the Bischler-Napieralski chloro-substituted iminium salt. Sodium borohydride reduction of iminium intermediate I resulting from the cyclization of $\mathbf{H}$ stereoselectively afforded desired compound $\mathbf{7 8}$ as a single isomer (Scheme 29). ${ }^{57}$

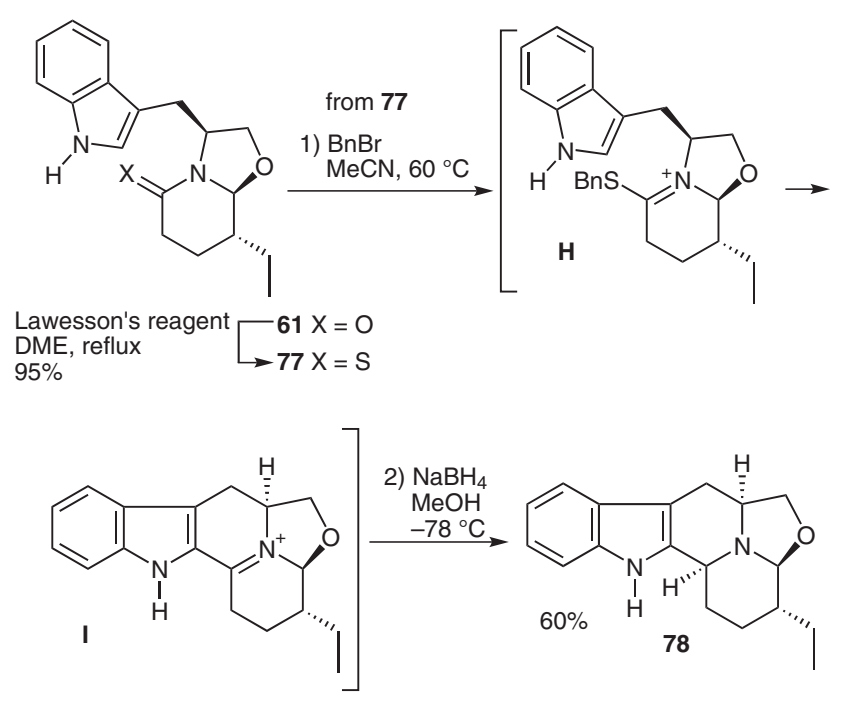

Scheme 29

With a method in hand for the regio- and stereoselective cyclization involving the lactam carbonyl moiety of $(S)$ tryptophanol-derived bicyclic lactams, the enantioselective synthesis of the indole alkaloids (+)-dihydrocorynantheine and (-)-dihydrocorynantheol is possible starting from appropriately substituted derivatives. Thus, lactam 64, incorporating an acetate chain at C-7 of the bicyclic system and a C-8 ethyl substituent with the required trans$R, R$ configuration, was converted into the corresponding thioamide 79, which was then subjected to the modified Bischler-Napieralski conditions as in the above model series. In this way, compound $\mathbf{8 0}$ was isolated in $60 \%$ yield as a single stereoisomer (Scheme 30). The absolute configuration of the stereogenic center generated in the reaction was unambiguously established by X-ray crystallographic analysis of the alcohol resulting from the borane reduction of compound $\mathbf{8 0}$. To complete the synthesis of the precursor to the target alkaloids, we only needed to remove the hydroxymethyl appendage. To per- 

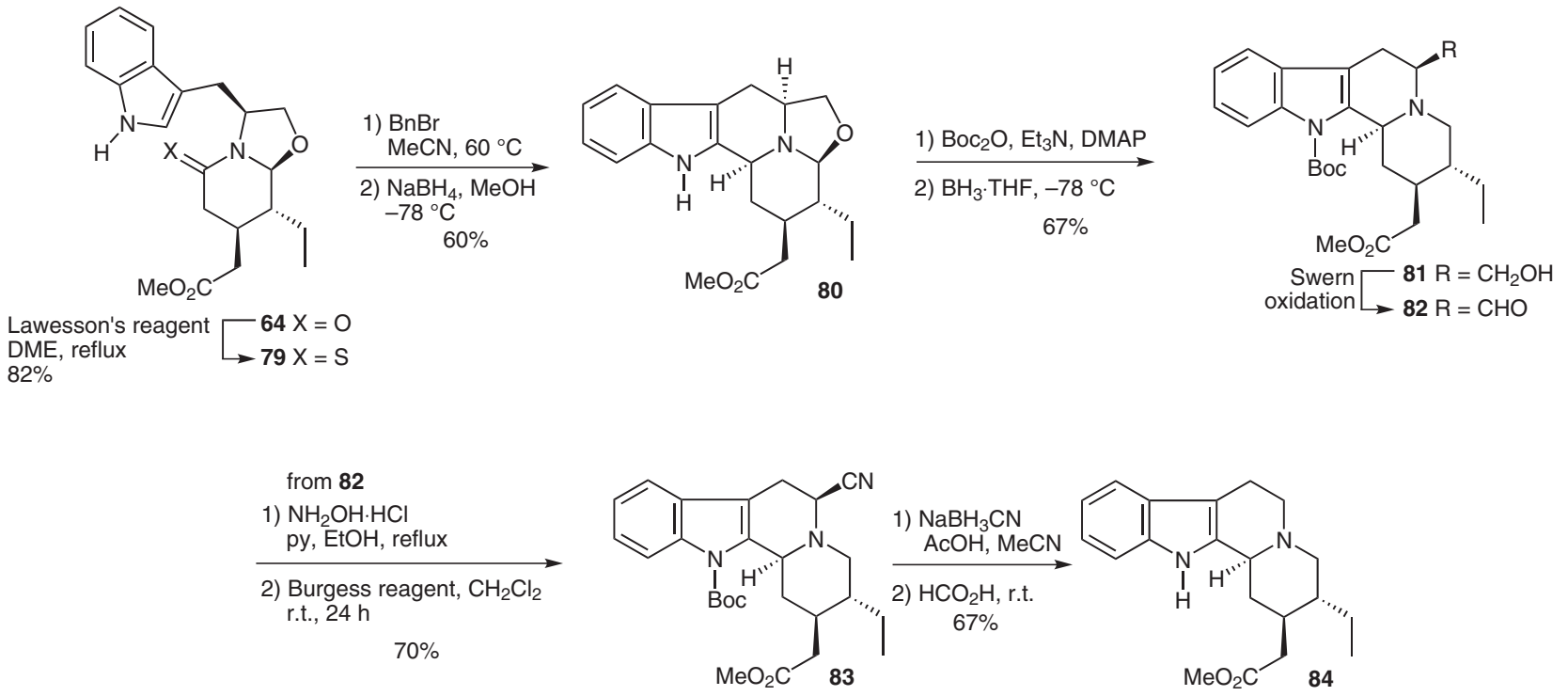

Scheme 30

form this transformation, we initially planned to use Allin's procedure involving, as a key step, the radical reductive decarbonylation of a selenoester (see Scheme 26). The indole nitrogen of compound $\mathbf{8 0}$ was protected as an $\mathrm{N}$-Boc derivative and the oxazolidine ring of the resulting pentacyclic compound was subjected to reductive ring opening with borane to give $\mathbf{8 1}$. However, all attempts to oxidize either alcohol $\mathbf{8 1}$ or aldehyde $\mathbf{8 2}$ to give the corresponding carboxylic acid were unsuccessful. At this point, we envisaged an alternative methodology to remove the hydroxymethyl substituent: reductive decyanation of an $\alpha$-amino nitrile. To this end, aldehyde 82 was converted into an oxime, which was subsequently dehydrated with the Burgess reagent to give $\alpha$-amino nitrile 83. Treatment of $\mathbf{8 3}$ with sodium cyanoborohydride, followed by indole deprotection, led to the target indoloquinolizidine 84.57

Compound 84 is a known precursor of the alkaloids (+)dihydrocorynantheine ${ }^{58,59}$ and (-)-dihydrocorynantheol, ${ }^{60}$ so the above sequence represents a formal total synthesis of these alkaloids ${ }^{61}$ (Figure 12). Moreover, taking into account previous correlations, ${ }^{62}$ the synthesis of tetracycle 84 also constitutes a formal synthesis of the oxindole alkaloids (-)-rhynchophylline and (+)-isorhynchophylline. $^{63}$

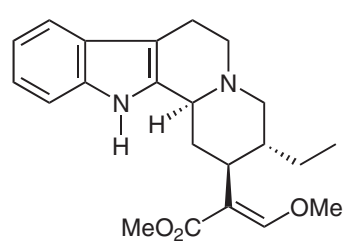

(+)-dihydrocorynantheine

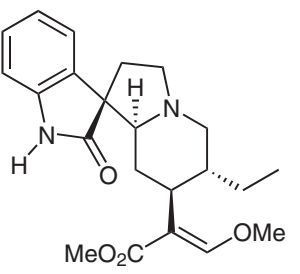

(-)-rhynchophylline

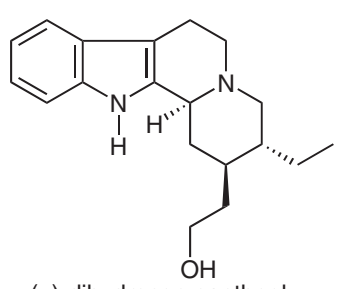

(-)-dihydrocorynantheol

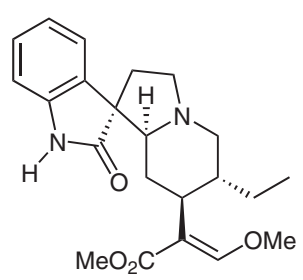

(+)-isorhynchophylline

Figure 12

ful building blocks that allow not only the regio- and stereocontrolled introduction of substituents at different positions of the piperidine ring, but also the enantioselective synthesis of complex piperidine-containing indole alkaloids belonging to a variety of structural types.

\section{Acknowledgment}

Financial support from the Ministerio de Ciencia e Innovación (MICINN), Spain (Projects CTQ2006-02390/BQU and CTQ200907021/BQU), and the Agència de Gestió d'Ajuts Universitaris i de Recerca (AGAUR), Generalitat de Catalunya (Grants 2005-SGR0603 and 2009-SGR-1111), is gratefully acknowledged.

Chiral, nonracemic phenylglycinol- and tryptophanolderived oxazolopiperidone lactams are exceptionally use- 


\section{References}

(1) (a) Strunz, G. M.; Findlay, J. A. In The Alkaloids, Vol. 26; Brossi, A., Ed.; Academic: London, 1985, 89-183. (b) Takahata, H.; Momose, T. In The Alkaloids, Vol. 44; Cordell, G. A., Ed.; Academic: San Diego, 1993, 189-256. (c) Ohmiya, S.; Saito, K.; Murakoshi, I. In The Alkaloids, Vol. 47; Cordell, G. A., Ed.; Academic: San Diego, 1995, 1-114. (d) Schneider, M. J. In Alkaloids: Chemical and Biological Perspectives, Vol. 10; Pelletier, S. W., Ed.; Pergamon: Oxford, 1996, 155-299. (e) Andersen, R. J.; Van Soest, R. W. M.; Kong, F. In Alkaloids: Chemical and Biological Perspectives, Vol. 10; Pelletier, S. W., Ed.; Pergamon: Oxford, 1996, 301-355. (f) Daly, J. W.; Garraffo, H. M.; Spande, T. F. In Alkaloids: Chemical and Biological Perspectives, Vol. 13; Pelletier, S. W., Ed.; Pergamon: New York, 1999, 1-161. (g) Watson, P. S.; Jiang, B.; Scott, B. Org. Lett. 2000, 2, 3679-3681. (h) Michael, J. P. Nat. Prod. Rep. 2005, 22, 603-626.

(2) (a) Angle, S. R.; Breitenbucher, J. G. In Studies in Natural Products Chemistry, Vol. 16; Atta-ur-Rahman, Ed.; Elsevier: Amsterdam, 1995, 453-502. (b) Laschat, S.; Dickner, T. Synthesis 2000, 1781. (c) Guilloteau-Bertin, B.; Compère, D.; Gil, L.; Marazano, C.; Das, B. C. Eur. J. Org. Chem. 2000, 1391. (d) Weintraub, P. M.; Sabol, J. S.; Kane, J. M.; Borcherding, D. R. Tetrahedron 2003, 59, 2953. (e) Horton, D. A.; Bourne, G. T.; Smythe, M. L. Chem. Rev. 2003, 103, 893. (f) Buffat, M. G. P. Tetrahedron 2004, 60, 1701. (g) Pearson, M. S. M.; Mathe-Allainmat, M.; Fargeas, V.; Lebreton, J. Eur. J. Org. Chem. 2005, 2159. (h) Fraser, H. L.; Floyd, M. B.; Sosa, A. C. B. Prog. Heterocycl. Chem. 2005, 17, 261. (i) Huang, P.-Q. Synlett 2006, 1133. (j) De Risis, C.; Fanton, G.; Pollini, G. P.; Trapella, C.; Valente, F.; Zanirato, V. Tetrahedron: Asymmetry 2008, 19, 131. (k) Kaellstroem, S.; Leino, R. Bioorg. Med. Chem. 2008, 16, 601. (1) Vicario, J. L.; Badía, D.; Carrillo, L.; Ruiz, N.; Reyes, E. In Targets in Heterocyclic Systems: Chemistry and Properties, Vol. 12; Attanasi, O. A.; Spinelli, D., Eds.; Italian Society of Chemistry: Rome, 2008, 302-327.

(3) (a) Romo, D.; Meyers, A. I. Tetrahedron 1991, 47, 9503. See also: (b) Stereocontrolled Organic Synthesis; Trost, B. M., Ed.; Blackwell: Oxford, 1994.

(4) Meyers, A. I.; Brengel, G. P. Chem. Commun. (Cambridge) 1997, 1.

(5) Groaning, M. D.; Meyers, A. I. Tetrahedron 2000, 56, 9843.

(6) (a) Amat, M.; Llor, N.; Hidalgo, J.; Bosch, J.; Molins, E.; Miravitlles, C. Tetrahedron: Asymmetry 1996, 7, 2501. (b) Amat, M.; Llor, N.; Bosch, J.; Solans, X. Tetrahedron 1997, 53, 719. (c) Amat, M.; Bosch, J.; Hidalgo, J.; Cantó, M.; Pérez, M.; Llor, N.; Molins, E.; Miravitlles, C.; Orozco, M.; Luque, J. J. Org. Chem. 2000, 65, 3074. (d) Amat, M.; Llor, N.; Huguet, M.; Molins, E.; Espinosa, E.; Bosch, J. Org. Lett. 2001, 3, 3257. (e) Amat, M.; Cantó, M.; Llor, N.; Bosch, J. Chem. Commun. (Cambridge) 2002, 526. (f) Amat, M.; Llor, N.; Escolano, C.; Huguet, M.; Pérez, M.; Molins, E.; Bosch, J. Tetrahedron: Asymmetry 2003, 14, 293. (g) Amat, M.; Llor, N.; Hidalgo, J.; Escolano, C.; Bosch, J. J. Org. Chem. 2003, 68, 1919. (h) Amat, M.; Escolano, C.; Llor, N.; Huguet, M.; Pérez, M.; Bosch, J. Tetrahedron: Asymmetry 2003, 14, 1679. (i) Casamitjana, N.; Amat, M.; Llor, N.; Carreras, M.; Pujol, X.; Fernández, M. M.; López, V.; Molins, E.; Miravitlles, C.; Bosch, J. Tetrahedron: Asymmetry 2003, 14, 2033. (j) Amat, M.; Huguet, M.; Llor, N.; Bassas, O.; Gomez, A. M.; Bosch, J.; Badia, J.; Baldoma, L.; Aguilar, J. Tetrahedron Lett. 2004, 45,5355 .
(7) (a) Amat, M.; Cantó, M.; Llor, N.; Ponzo, V.; Pérez, M.; Bosch, J. Angew. Chem. Int. Ed. 2002, 41, 335. (b) Amat, M.; Cantó, M.; Llor, N.; Escolano, C.; Molins, E.; Espinosa, E.; Bosch, J. J. Org. Chem. 2002, 67, 5343. (c) Amat, M.; Bassas, O.; Pericàs, M. A.; Pastó, M.; Bosch, J. Chem. Commun. (Cambridge) 2005, 1327. (d) Amat, M.; Bassas, O.; Llor, N.; Cantó, M.; Pérez, M.; Molins, E.; Bosch, J. Chem. Eur. J. 2006, 12, 7872. See also: (e) Amat, M.; Pérez, M.; Llor, N.; Bosch, J.; Lago, E.; Molins, E. Org. Lett. 2001, 3, 611. (f) Amat, M.; Pérez, M.; Llor, N.; Bosch, J. Org. Lett. 2002, 4, 2787. (g) Amat, M.; Pérez, M.; Minaglia, A. T.; Casamitjana, N.; Bosch, J. Org. Lett. 2005, 7, 3653. (h) Soteras, I.; Lozano, O.; Gómez-Esqué, A.; Escolano, C.; Orozco, M.; Amat, M.; Bosch, J.; Luque, F. J. J. Am. Chem. Soc. 2006, 128, 6581. (i) Amat, M.; Escolano, C.; GómezEsqué, A.; Lozano, O.; Llor, N.; Griera, R.; Molins, E.; Bosch, J. Tetrahedron: Asymmetry 2006, 17, 1581. (j) Allin, S. M.; Duffy, L. J.; Bulman Page, P. C.; McKee, V.; Edgar, M.; McKenzie, M. J.; Amat, M.; Bassas, O.; Santos, M. M. M.; Bosch, J. Tetrahedron Lett. 2006, 47, 5713. (k) Amat, M.; Pérez, M.; Minaglia, A. T.; Peretto, B.; Bosch, J. Tetrahedron 2007, 63, 5839. (1) Amat, M.; Pérez, M.; Minaglia, A. T.; Bosch, J. J. Org. Chem. 2008, 73, 6920. (m) Amat, M.; Pérez, M.; Minaglia, A. T.; Passarella, D.; Bosch, J. Tetrahedron: Asymmetry 2008, 19, 2406. (n) Amat, M.; Brunaccini, E.; Checa, B.; Pérez, M.; Llor, N.; Bosch, J. Org. Lett. 2009, 11, 4370. (o) Amat, M.; Pérez, M.; Proto, S.; Gatti, T.; Bosch, J. Chem. Eur. J. 2010, 16, 9438.

(8) (a) Amat, M.; Griera, R.; Fabregat, R.; Molins, E.; Bosch, J. Angew. Chem. Int. Ed. 2008, 47, 3348. (b) Amat, M.; Fabregat, R.; Griera, R.; Bosch, J. J. Org. Chem. 2009, 74, 1794. (c) Amat, M.; Fabregat, R.; Griera, R.; Florindo, P.; Molins, E.; Bosch, J. J. Org. Chem. 2010, 75, 3797.

(9) Escolano, C.; Amat, M.; Bosch, J. Chem. Eur. J. 2006, 12, 8198.

(10) Gaskell, S. N.; Duffy, L. J.; Allin, S. M. Nat. Prod. Commun. 2008, 3, 1825 .

(11) (a) Indoles: The Monoterpenoid Indole Alkaloids, In The Chemistry of Heterocyclic Compounds, Vol. 25, Part 4; Saxton, J. E.; Weissberger, A.; Taylor, E. C., Eds.; Wiley: New York, 1983. (b) Monoterpenoid Indole Alkaloids, In The Chemistry of Heterocyclic Compounds, Suppl. to Vol. 25, Part 4; Saxton, J. E.; Taylor, E. C., Eds.; Wiley: Chichester, 1994. See also: (c) Leonard, J. Nat. Prod. Rep. 1999, 16, 319. (d) Borschberg, H.-J. Curr. Org. Chem. 2005, 9, 1465. (e) Edwankar, C. R.; Edwankar, R. V.; Namjoshi, O. A.; Rallapalli, S. K.; Yang, J.; Cook, J. M. Curr. Opin. Drug Discovery Dev. 2009, 12, 752.

(12) (a) O'Connor, S. E.; Maresh, J. J. Nat. Prod. Rep. 2006, 23, 532. (b) Stöckigt, J.; Barleben, L.; Panjikar, S.; Loris, E. A. Plant Physiol. Biochem. 2008, 46, 340.

(13) (a) Danieli, B.; Palmisano, G. In The Alkaloids, Vol. 27; Brossi, A., Ed.; Academic: Orlando, 1986, 1-130. (b) Scott, A. I. Acc. Chem. Res. 1970, 3, 151.

(14) Amat, M.; Llor, N.; Hidalgo, J.; Bosch, J. Tetrahedron: Asymmetry 1997, 8, 2237.

(15) Amat, M.; Escolano, C.; Llor, N.; Lozano, O.; GómezEsqué, A.; Griera, R.; Bosch, J. ARKIVOC 2005, (ix), 115.

(16) (a) Amat, M.; Pshenichnyi, G.; Bosch, J.; Molins, E.; Miravitlles, C. Tetrahedron: Asymmetry 1996, 7, 3091. (b) See also ref. 15

(17) (a) Crooks, P. A.; Robinson, B.; Smith, G. F. Chem. Commun. 1968, 1210. For further isolations from other species, see: (b) Robert, G. M. T.; Ahond, A.; Poupat, C.; Potier, P.; Jollés, C.; Jousselin, A.; Jacquemin, H. J. Nat. Prod. 1983, 46, 694. (c) Atta-ur-Rahman; Zaman, K.; 
Perveen, S.; Habib-ur-Rehman; Muzaffar, A.; Choudhary, M. I.; Pervin, A. Phytochemistry 1991, 30, 1285.

(d) Mroue, M. A.; Ghuman, M. A.; Alam, M. Phytochemistry 1993, 33, 217.

(18) Palmisano, G.; Santagostino, M.; Riva, S.; Sisti, M. Tetrahedron: Asymmetry 1995, 6, 1229.

(19) Amat, M.; Hadida, S.; Sathyanarayana, S.; Bosch, J. J. Org. Chem. 1994, 59, 10.

(20) (a) Battersby, A. R.; Parry, R. J. J. Chem. Soc. D 1971, 901. (b) Jain, S.; Sinha, A.; Bhakuni, D. S. Phytochemistry 2002, 60,853 .

(21) (a) Uskokovic, M.; Reese, C.; Lee, H. L.; Grethe, G.; Gutzwiller, J. J. Am. Chem. Soc. 1971, 93, 5902.

(b) Uskokovic, M. R.; Henderson, T.; Reese, C.; Lee, H. L.; Grethe, G.; Gutzwiller, J. J. Am. Chem. Soc. 1978, 100, 571. (c) Fujii, T.; Ohba, M.; Yoneyama, K.; Kizu, H. Chem. Pharm. Bull. 1985, 33, 358. (d) Minato, D.; Imai, M.; Kanda, Y.; Onomura, O.; Matsumura, Y. Tetrahedron Lett. 2006, 47, 5485 .

(22) (a) Fujii, T.; Yoshifuji, S.; Tai, M. Chem. Pharm. Bull. 1975, 23, 2094. (b) Fujii, T.; Ohba, M. Chem. Pharm. Bull. 1985, 33, 583. (c) Brown, R. T.; Leonard, J. Tetrahedron Lett. 1978, 19, 1605.

(23) (a) Hirai, Y.; Terada, T.; Yamazaki, T.; Momose, T. J. Chem. Soc., Perkin Trans. 1 1992, 517. See also: (b) Hirai, Y.; Terada, T.; Yamazaki, T.; Momose, T. J. Chem. Soc., Perkin Trans. 1 1992, 509.

(24) Amat, M.; Pérez, M.; Llor, N.; Escolano, C.; Luque, F. J.; Molins, E.; Bosch, J. J. Org. Chem. 2004, 69, 8681.

(25) Deslongchamps, P. In Stereoelectronic Effects in Organic Chemistry; Pergamon: Oxford, 1983, 221.

(26) Perlmutter, P. In Conjugate Addition Reactions in Organic Synthesis; Pergamon: Oxford, 1992, 25.

(27) (a) Fujii, T.; Ohba, M.; Yoneyama, K.; Kizu, H.; Yoshifuji, S. Chem. Pharm. Bull. 1986, 34, 669. (b) Fujii, T.; Ohba, M. Heterocycles 1998, 47, 525; and references cited therein.

(28) (a) Edwin, S. J. In The Alkaloids, Vol. 50; Cordell, G. A., Ed.; Academic: San Diego, 1998, 343-376. (b) Overman, L. E.; Sworin, M. In Alkaloids: Chemical and Biological Perspectives, Vol. 3; Pelletier, S. W., Ed.; John Wiley and Sons: New York, 1985, 275-307. (c) Cordell, G. A. In The Alkaloids, Vol. 17; Manske, R. H. F.; Rodrigo, R. G. A., Eds.; Academic: New York, 1979, 199-384.

(29) (a) Sundberg, R. J.; Smith, S. Q. In The Alkaloids, Vol. 59; Cordell, G. A., Ed.; Elsevier: San Diego, 2002, 281-386. (b) Takayama, H.; Sakai, S.-I. In The Alkaloids, Vol. 50; Cordell, G. A., Ed.; Elsevier: San Diego, 1998, 415-452.

(30) Amat, M.; Lozano, O.; Escolano, C.; Molins, E.; Bosch, J. J. Org. Chem. 2007, 72, 4431.

(31) (a) Ziegler, F. E.; Kloek, J. A.; Zoretic, P. A. J. Am. Chem. Soc. 1969, 91, 2342. See also: (b) Ziegler, F. E.; Bennett, G. B. J. Am. Chem. Soc. 1973, 95, 7458.

(32) Takano, S.; Sato, M.; Hatakema, S.; Hirama, M.; Ogasawara, K. Heterocycles 1976, 5, 221.

(33) (a) Takano, S.; Yonaga, M.; Ogasawara, K. J. Chem. Soc., Chem. Commun. 1981, 1153. (b) Node, M.; Nagasawa, H.; Fuji, K. J. Org. Chem. 1990, 55, 517. (c) Kozmin, S. A.; Iwama, T.; Huang, Y.; Rawal, V. H. J. Am. Chem. Soc. 2002, 124, 4628. (d) Sattely, E. S.; Meek, S. J.; Malcolmson, S. J.; Schrock, R. R.; Hoveyda, A. H. J. Am. Chem. Soc. 2009, 131, 943.

(34) Amat, M.; Escolano, C.; Lozano, O.; Gómez-Esqué, A.; Griera, R.; Molins, E.; Bosch, J. J. Org. Chem. 2006, 71, 3804.

(35) For a preliminary account of this work, see: Amat, M.; Escolano, C.; Lozano, O.; Llor, N.; Bosch, J. Org. Lett. 2003, 5, 3139.
(36) Danieli, B.; Lesma, G.; Passarella, D.; Silvani, A. Tetrahedron Lett. 2000, 41, 3489.

(37) Kanada, R. M.; Ogasawara, K. Tetrahedron Lett. 2001, 42, 7311.

(38) (a) Joule, J. A. Indoles: The Monoterpenoid Indole Alkaloids, In The Chemistry of Heterocyclic Compounds, Vol. 25, Part 4; Saxton, J. E.; Weissberger, A.; Taylor, E. C., Eds.; Wiley: New York, 1983, Chap. 6. (b) Alvarez, M.; Joule, J. A. Monoterpenoid Indole Alkaloids, In The Chemistry of Heterocyclic Compounds, Suppl. to Vol. 25, Part 4; Saxton, J. E.; Taylor, E. C., Eds.; Wiley: Chichester, 1994, Chap. 6. (c) Alvarez, M.; Joule, J. A. In The Alkaloids, Vol. 57; Cordell, G. A., Ed.; Academic: New York, 2001, Chap. 4.

(39) Amat, M.; Llor, N.; Checa, B.; Pérez, M.; Bosch, J. Tetrahedron Lett. 2007, 48, 6722.

(40) For a preliminary account of this work, see: Amat, M.; Pérez, M.; Llor, N.; Martinelli, M.; Molins, E.; Bosch, J. Chem. Commun. (Cambridge) 2004, 1602.

(41) Saito, M.; Kawamura, M.; Hiroya, K.; Ogasawara, K. Chem. Commun. (Cambridge) 1997, 765.

(42) (a) Joule, J. A.; Ohashi, M.; Gilbert, B.; Djerasi, C. Tetrahedron 1965, 21, 1717. (b) Gràcia, J.; Casamitjana, N.; Bonjoch, J.; Bosch, J. J. Org. Chem. 1994, 59, 3939.

(43) Ishikura, M.; Takahashi, N.; Yamada, K.; Abe, T. Heterocycles 2008, 75, 107.

(44) Wu, A.; Snieckus, V. Tetrahedron Lett. 1975, 16, 2057.

(45) Amat, M.; Coll, M.-D.; Bosch, J.; Espinosa, E.; Molins, E. Tetrahedron: Asymmetry 1997, 8, 935.

(46) (a) Joule, J. A. Indoles: The Monoterpenoid Indole Alkaloids, In The Chemistry of Heterocyclic Compounds, Vol. 25, Part 4; Saxton, J. E.; Weissberger, A.; Taylor, E. C., Eds.; Wiley: New York, 1983, 232. (b) See also ref. 13a. For more-recent isolations, see: (c) Zhang, H.; Yue, J.-M. Helv. Chim. Acta 2005, 88, 2537.

(47) Amat, M.; Llor, N.; Checa, B.; Molins, E.; Bosch, J. J. Org. Chem. 2010, 75, 178.

(48) For related synthetic studies on the ervatamine-silicine group, see: (a) Husson, H.-P.; Bannai, K.; Freire, R.; Mompon, B.; Reis, F. A. M. Tetrahedron 1978, 34, 1363. (b) Bennasar, M.-L.; Vidal, B.; Bosch, J. J. Org. Chem. 1997, 62, 3597. (c) Bennasar, M.-L.; Vidal, B.; Kumar, R.; Lázaro, A.; Bosch, J. Eur. J. Org. Chem. 2000, 3919 . For the synthesis of tetracyclic structures related to ervataminesilicine alkaloids, see: (d) Langlois, Y.; Potier, P. Tetrahedron 1975, 31, 423. (e) Grierson, D. S.; Bettiol, J.-L.; Buck, I.; Husson, H.-P.; Rubiralta, M.; Diez, A. J. Org. Chem. 1992, 57, 6414.

(49) For a preliminary account of this work, see: Amat, M.; Checa, B.; Llor, N.; Molins, E.; Bosch, J. Chem. Commun. (Cambridge) 2009, 2935.

(50) For a review of the work developed by S. M. Allin in this field, see: ref. 10

(51) (a) Bassas, O.; Llor, N.; Santos, M. M. M.; Griera, R.; Molins, E.; Amat, M.; Bosch, J. Org. Lett. 2005, 7, 2817. (b) Amat, M.; Santos, M. M. M.; Bassas, O.; Llor, N.; Escolano, C.; Gómez-Esqué, A.; Molins, E.; Allin, S. M.; McKee, V.; Bosch, J. J. Org. Chem. 2007, 72, 5193. See also: (c) Santos, M. M. M. In Heterocyclic Targets in Advanced Organic Synthesis; Carreiras, M. C.; MarcoContelles, J., Eds.; Research Signpost: Trivandrum / India, 2001, 69-82.

(52) Allin, S. M.; Thomas, C. I.; Allard, J. E.; Duncton, M.; Elsegood, M. R. J.; Edgar, M. Tetrahedron Lett. 2003, 44, 2335.

(53) (a) Allin, S. M.; Thomas, C. I.; Allard, J. E.; Doyle, K.; 
Elsegood, M. R. J. Tetrahedron Lett. 2004, 45, 7103. (b) Allin, S. M.; Thomas, C. I.; Allard, J. E.; Doyle, K.; Elsegood, M. R. J. Eur. J. Org. Chem. 2005, 4179.

(54) Allin, S. M.; Northfield, C. J.; Page, M. I.; Slawin, A. M. Z. Tetrahedron Lett. 1998, 39, 4905.

(55) Allin, S. M.; Gaskell, S. N.; Elsegood, M. R. J.; Martin, W. P. Tetrahedron Lett. 2007, 48, 5669.

(56) Allin, S. M.; Thomas, C. I.; Doyle, K.; Elsegood, M. R. J. J. Org. Chem. 2005, 70, 357.

(57) Amat, M.; G ómez-Esqué, A.; Escolano, C.; Santos, M. M. M.; Molins, E.; Bosch, J. J. Org. Chem. 2009, 74, 1205.

(58) Tietze, L. F.; Zhou, Y. Angew. Chem. Int. Ed. 1999, 38, 2045.

(59) (a) Weisbach, J. A.; Kirkpatrick, J. L.; Williams, K. R.; Anderson, E. L.; Yim, N. C.; Douglas, B. Tetrahedron Lett. 1965, 6, 3457. (b) Van Tamelen, E. E.; Hester, J. B. Jr. J. Am. Chem. Soc. 1969, 91, 7342 .
(60) (a) Brown, R. T.; Jones, M. F.; Wingfield, M. J. Chem. Soc., Chem. Commun. 1984, 847. (b) Diez, A.; Vila, C.; Sinibaldi, M. E.; Troin, Y.; Rubiralta, M. Tetrahedron Lett. 1993, 34, 733.

(61) For previous syntheses of (-)-dihydrocorynantheol, see: (a) Suzuki, T.; Sato, E.; Unno, K.; Kametani, T. Chem. Pharm. Bull. 1986, 34, 1584. (b) Beard, R. L.; Meyers, A. I. J. Org. Chem. 1991, 56, 2091. (c) Ohba, M.; Ohashi, T.; Fujii, T. Heterocycles 1991, 32, 319. (d) Itoh, T.; Tokoya, M.; Miyauchi, K.; Nagata, K.; Ohsawa, A. Org. Lett. 2006, 8, 1533. (e) Tosaka, A.; Ito, S.; Miyazawa, N.; Shibuya, M.; Ogasawara, K.; Iwabuchi, Y. Heterocycles 2006, 70, 153.

(62) Deiters, A.; Pettersson, M.; Martin, S. F. J. Org. Chem. 2006, $71,6547$.

(63) For the conversion of (-)-dihydrocorynantheine into (-)rhynchophylline and (+)-isorhynchophylline, see: Finch, N.; Taylor, W. I. J. Am. Chem. Soc. 1962, 84, 3871. 